\title{
Binding of Scandium Ions to Metalloporphyrin-Flavin Complexes for Long-Lived Charge Separation
}

\author{
Takahiko Kojima, ${ }^{\text {[a] }}$ Ryosuke Kobayashi, ${ }^{[a]}$ Tomoya Ishizuka, ${ }^{[a]}$ Shinya Yamakawa, ${ }^{[a]}$ Hiroaki \\ Kotani, ${ }^{[a]}$ Tatsuaki Nakanishi, ${ }^{[b]}$ Kei Ohkubo, ${ }^{[b]}$ Yoshihito Shiota, ${ }^{[c]}$ Kazunari Yoshizawa, ${ }^{[c]}$ and \\ Shunichi Fukuzumi*[b]
}

\begin{abstract}
A porphyrin-flavin linked dyad and its zinc and palladium complexes (MPor-Fl: $\mathbf{2}-\mathbf{M}, \mathbf{M}=\mathbf{2} \mathbf{H}, \mathbf{Z n}$ and $\mathbf{P d}$ ) were newly synthesized and the X-ray crystal structure of 2 $\mathbf{P d}$ was determined. The photodynamics of 2-M was examined by femtosecond and nanosecond laser flash photolysis measurements. Photoinduced electron transfer (ET) in $\mathbf{2}-\mathbf{H}_{2}$ occurred from the singlet excited state of the porphyrin moiety $\left(\mathrm{H}_{2} \mathrm{Por}\right)$ to the flavin $(\mathrm{Fl})$ moiety to produce the singlet chargeseparated (CS) state ${ }^{1}\left(\mathrm{H}_{2} \mathrm{Por}^{\circ+}-\mathrm{Fl}^{--}\right)$, which decayed via back ET (BET) to form ${ }^{3}\left[\mathrm{H}_{2} \mathrm{Por}\right]^{*}-\mathrm{Fl}$ with the rate constants of $1.2 \times$ $10^{10} \mathrm{~s}^{-1}$ and $1.2 \times 10^{9} \mathrm{~s}^{-1}$, respectively. Similarly photoinduced ET in 2-Pd afforded the singlet CS state which decayed via $\mathrm{BET}$ to form ${ }^{3}[\mathrm{PdPor}]^{*}-\mathrm{FI}$ with the rate constants of $2.1 \times 10^{11}$
\end{abstract}

$\mathrm{s}^{-1}$ and $6.0 \times 10^{10} \mathrm{~s}^{-1}$, respectively. The rate constant of photoinduced ET and BET of 2-M were related to the ET and BET driving forces using the Marcus theory of electron transfer. One and two $\mathrm{Sc}^{3+}$ ions bind to the flavin moiety to form the $\mathrm{Fl}-\mathrm{Sc}^{3+}$ and $\mathrm{Fl}-\left(\mathrm{Sc}^{3+}\right)_{2}$ complexes with binding constants of $K_{1}=2.2 \times 10^{5} \mathrm{M}^{-1}$ and $K_{2}=1.8 \times 10^{3} \mathrm{M}^{-1}$, respectively. Other metal ions such as $\mathrm{Y}^{3+}, \mathrm{Zn}^{2+}$ and $\mathrm{Mg}^{2+}$ form only $1: 1$ complexes with flavin. In contrast to $2-\mathbf{M}$ and the $1: 1$ complexes with metal ions, which afforded the short-lived singlet CS state, photoinduced ET in 2-Pd $\cdots \mathrm{Sc}^{3+}$ complexes afforded the triplet CS state $\left({ }^{3}\left[\mathrm{PdPor}^{\circ+}-\mathrm{Fl}^{--}-\left(\mathrm{Sc}^{3+}\right)_{2}\right]\right)$ exhibiting a remarkably long lifetime of $\tau=110 \mathrm{~ms}\left(k_{\mathrm{BET}}=9.1 \mathrm{~s}^{-1}\right)$.

\section{Introduction}

A long-lived charge-separated (CS) state formed by photoinduced electron transfer is indispensable to convert absorbed light energy into other energies as observed in photosynthesis, ${ }^{[1]}$ solar cells, ${ }^{[2]}$ photocatalysis for material production. ${ }^{[3]}$ For example, photoexcitation of a dimer of chlorophylls, so-called the special pair, in a well-organized donor and acceptor sequence in photosystem II (PS II), triggers a cascade of electron transfer (ET) reactions, in which the direction and the rates of ET are precisely regulated by metal ions bound to macrocycles and

[a] Mr. R. Kobayashi, Dr. T. Ishizuka, Mr. S. Yamakawa, Dr. H. Kotani, Prof. Dr. T. Kojima

Department of Chemistry, Graduate School of Pure and Applied Sciences, University of Tsukuba, 1-1-1 Tennoudai, Tsukuba, Ibaraki 305-8571 (Japan)

E-mail:kojima@chem.tsukuba.ac.jp

[b] Dr. T. Nakanishi, Dr. K. Ohkubo, Prof. Dr. S. Fukuzumi Department of Material and Life Science, Graduate School of Engineering, Osaka University, and ALCA, Japan Science and Technology Agency, Suita, Osaka 565-0871 (Japan) E-mail: fukuzumi@chem.eng.osaka-u.ac.jp

[c] Dr. Y. Shiota, Prof. Dr. K. Yoshizawa

Institute for Materials Chemistry and Engineering, Kyushu University, Motooka, Nishi-Ku, Fukuoka 819-0395 (Japan)

Supporting information for this article is available on the WWW under http://www.chemeurj.org/ or from the author. quinones. ${ }^{[4]}$ The sequential ET reactions afford the CS state showing the lifetime of $\sim 1 \mathrm{~s}$ to gain chemical energy that finally oxidize water to form $\mathrm{O}_{2}$ and reduce the quinone $\mathrm{B}$ as the final electron acceptor. ${ }^{[4-6]}$ Furthermore, the triplet excited state of the special pair, which is formed by back ET of primary ET, is quenched effectively by carotenoids before it reacts with the ground-state dioxygen in the triplet state to form the highly toxic singlet dioxygen. ${ }^{[7]}$ Thus, for establishing effective photocatalytic systems, it is necessary for the photocatalysts not only to form a long-lived CS state but also to quench a triplet state by modulating their energy levels and controlling their photodynamics.

A large number of donor-acceptor (D-A) linked molecules mimicking PS II have been synthesized to attain a long-lived CS state via multistep electron transfer started from a singlet excited state. ${ }^{[8-18]}$ In order to avoid energy loss and synthetic difficulties, directly linked D-A dyads have been found to be useful for forming long-lived CS states. ${ }^{[19]}$ Another approach to attain a long-lived CS state is the formation of a triplet CS state: ${ }^{[20,21]}$ The relaxation from the triplet CS state to the singlet ground state is spin-forbidden. Smit and Warman have first reported that carbazole-tetrachlorophthalimide compounds exhibit the lifetimes of the triplet CS states in ca. microsecond range, which are $10-$ 500 times longer than those of the singlet CS states. ${ }^{[20]}$ Electrondonor-substituted 3-ethoxycarbonylcoumarin (CM) derivatives also exhibited over $10^{5}$ times elongation of the triplet CS state in comparison with the lifetime of the corresponding singlet CS state. ${ }^{[21]}$ Additionally, the quantum yield of the triplet CS state increased in the presence of iodobenzene due to the heavy atom effect. Accordingly, fast formation of a triplet excited state supported by a metal ion can be a useful strategy to attain a long- 
lived triplet CS state.

In order to perform photoinduced ET to generate CS states, porphyrins and their metal complexes have been serving as versatile electron donors exhibiting strong absorptions in the visible region. Their redox potentials and physicochemical properties are tunable by peripheral substituents and central metal ions. ${ }^{[22]}$ Additionally, heavy metal complexes of porphyrins (metal $=\mathrm{Pt}^{\prime \prime}, \mathrm{Pd}^{\prime \prime}$, etc. $)$ immediately form triplet excited states in high quantum yields by photoirradiation due to efficient intersystem crossing. ${ }^{[23]}$ Therefore, porphyrins have been linked to various kinds of electron acceptors including fullerenes and quinones to provide D-A dyads that form CS states upon photoexcitation. ${ }^{[8]}$

Recently, oxidized forms of flavin derivatives have been demonstrated to act as an electron acceptor in photoinduced ET to afford a long-lived CS state due to their small reorganization energies of ET. ${ }^{[24]}$ Flavins are structurally and functionally diverse redox-active coenzymes to perform a variety of thermal and photoinduced electron-transfer processes over a wide range of redox potentials. ${ }^{[25,26]}$ Furthermore, oxidized forms of flavins are known to bind various metal ions, giving rise to a positive shift of their one-electron reduction potentials. ${ }^{[27]}$ Although both flavins and porphyrins afford relatively small reorganization energies of $E T,{ }^{[24,28]}$ the ensembles of porphyrin analogs with flavin derivatives have so far been reported to exhibit only short lifetimes of singlet CS states to be sub-nanoseconds. ${ }^{[29]}$ Binding of metal ions to the electron acceptor moieties, which are linked with porphyrins, has been reported to elongate the CS lifetimes. ${ }^{[30]}$ However, neither formation of a long-lived triplet CS state of metalloporphyrin-flavin complexes nor the effect of metal ion binding has so far been reported.

We report herein design and synthesis of a porphyrin-flavin linked dyad and its zinc and palladium complexes (MPor-FI, 2-M $\mathbf{M}=\mathbf{2} \mathbf{H}, \mathbf{Z n}$ and $\mathbf{P d}$ ), their photoinduced ET properties, and the effect of binding of scandium ions to the flavin moiety of 2-Pd on the photodynamics. The X-ray crystal structure of 2-Pd was successfully determined. The energy levels of the CS states of the Por-Fl dyads can be controlled by the central metals of the porphyrin moiety and also by binding of scandium ions as a strong Lewis acid to the flavin moiety. Photodynamics of 2-M was examined in detail by femtosecond and nanosecond laser flash photolysis measurements. The rate constants of photoinduced ET to produce the singlet CS state and the BET reactions to give the triplet excited state or the ground state were analyzed in light of the Marcus theory of electron transfer. In each case, no triplet CS state was produced because only the short-lived singlet CS state was formed or the energy of the triplet excited state was higher than the triplet excited state of the porphyrin moiety. In contrast, when $\mathrm{Sc}^{3+}$ ions are bound to $\mathbf{2 - P d}$, the energy of the triplet CS state became significantly lower than the triplet excited state of the porphyrin moiety because of the strong binding $\mathrm{Sc}^{3+}$ ions to the flavin moiety, affording the long-lived triplet CS state with the lifetime of subsecond $(\sim 0.1 \mathrm{~s})$. The reason why the spin-allowed intermolecular decay of the triplet CS state was slower than the spin-forbidden intramolecular decay was clarified by examining the driving force dependence of the rate constants of bimolecular electron transfer from ferrocene derivatives to the $\mathrm{Fl}-\left(\mathrm{Sc}^{3+}\right)_{2}$ complex.

\section{Experimental Section}

General. Chemicals were purchased from commercial sources and used as received, unless otherwise noted. Benzonitrile $(\mathrm{PhCN})$ was distilled over $\mathrm{P}_{2} \mathrm{O}_{5}$ Scandium triflate $\left(\mathrm{Sc}(\mathrm{OTf})_{3}\right)$, Yttrium triflate $\left(\mathrm{Y}(\mathrm{OTf})_{3}\right)$, zinc triflate $\left(\mathrm{Zn}(\mathrm{OTf})_{2}\right)$ were purchased from Aldrich. Magnesium perchlorate $\left(\mathrm{Mg}\left(\mathrm{ClO}_{4}\right)_{2}\right)$ was obtained from Wako Pure Chemicals. Tetra- $n$-butyl-ammonium hexafluorophosphate $\left(\right.$ TBAPF $\left._{6}\right)$ was recrystallized from ethanol before use. Tetrakis(3,5-di-tert-butylphenyl)porphyrin $\left(\mathrm{H}_{2} \mathrm{Por}\right)^{[31]}$ was obtained as a by-product in the course of syntheses of porphyrin-flavin linked dyads. The Pd" complex (PdPor) ${ }^{[32]}$ was synthesized with the reaction of $\mathrm{H}_{2} \mathrm{Por}$ with $\mathrm{Pd}(\mathrm{OAc})_{2}$. 3,5-Di-tertbutylbenzaldehyde and meso-[3,5-di-(tert-butyl)phenyl]dipyrromethane were synthesized by following literature procedures. ${ }^{[33,34]} 10-N$-Decyl-isoalloxazine (DecFl) was prepared in a similar procedure described in the literature. ${ }^{[35]}$ The synthetic details of the compounds were described in Supporting Information (SI)

Absorption spectra were measured on a Hewlett Packard 8453 diode array spectrophotometer and a Shimadzu UV-2450 spectrometer at room temperature. Fluorescence spectra were recorded on an absolute PL quantum yield measurement system (Hamamatsu Photonics, C9920-02) Phosphorescence spectra were measured on a Shimadzu RF-5300PC and HORIBA Fluorolog spectrofluorophotometers. Samples for phosphorescence measurements were prepared according to the following procedure: 2 methyltetrahydrofuran solution of the PdPor, which was degassed by freezepump-thaw cycles, was introduced into a quartz tube $(3 \mathrm{~mm})$ and the sample tube was cooled to $77 \mathrm{~K}$ in the quartz Dewar cell filled with liquid nitrogen to afford the glass state of the sample solution. ${ }^{1} \mathrm{H}$ NMR spectra were measured on a JEOL AL-300 and EX270 spectrometers at room temperature and chemical shifts were determined by using the residual solvent peak as a reference. ${ }^{[36]}$ MALDI-TOF-MS measurements were performed on a Kratos Compact MALDI I (Shimadzu corporation) and Bruker BIFLEX III spectrometers

X-ray Crystallography on 2-Pd. A single crystal of 2-Pd was obtained by recrystallization with slow evaporation of the $\mathrm{CHCl}_{3}$ solution in the presence of $\mathrm{MeOH}$ as a poor solvent. All measurements were performed at $120 \mathrm{~K}$ on a Bruker APEXII Ultra diffractometer. The structure was solved by a direct method (SIR-97) and expanded with differential Fourier technique. All non-hydrogen atoms were refined anisotropically and the refinement was carried out with full matrix least squares on $F$. All calculations were performed using the YadokariXG crystallographic software package. ${ }^{[37]}$ Crystallographic data: $\mathrm{C}_{78} \mathrm{H}_{80} \mathrm{~N}_{8} \mathrm{O}_{2} \mathrm{Pd}$, $\mathrm{FW}=1267.90$, red-orange, monoclinic, $C 2 / c, a=39.035(13) \AA, b=9.628(3) \AA$, $c=47.196(16) \AA, \beta=113.099(4)^{\circ}, V=16314(9) \AA^{3}, Z=8, D_{\text {calcd }}=1.032 \mathrm{~g} \mathrm{~cm}^{-3}$, $F_{000}=5328, R 1=0.0703(I>2.00 \sigma(I)), w R 2=0.1751$ (all data), GOF $=0.944$. Highly disordered $\mathrm{CHCl}_{3}$ molecules as the solvent molecules of crystallization were deleted using the SQUEEZE program. ${ }^{[38]}$ Crystallographic details are available in the cif format as SI.

Electrochemical Measurements. Cyclic voltammetry (CV), differential pulse voltammetry (DPV), and second-harmonic ac voltammetry (SHACV) were performed on BAS ALS-630B and ALS-610 electrochemical analyzers in deaerated $\mathrm{PhCN}$ containing $0.1 \mathrm{M}$ TBAPF$_{6}$ as a supporting electrolyte at $298 \mathrm{~K}$. A conventional three-electrode cell was used with a platinum working electrode (surface area of $12 \mathrm{~mm}^{2}$ ) and a platinum wire as the counter electrode. The $\mathrm{Pt}$ working electrode (BAS) was routinely polished with BAS polishing alumina suspension and rinsed with distilled water and acetone before use. The potentials were measured with respect to the $\mathrm{Ag}_{\mathrm{AgNO}}(10 \mathrm{mM})$ or $\mathrm{Ag} / \mathrm{AgCl}$ wire as a reference electrode. All potentials ( $\mathrm{vs} \mathrm{Ag} / \mathrm{Ag}^{+}$) were converted to values vs. SCE by adding $0.29 \mathrm{~V}{ }^{[39]}$ or otherwise ferrocene $(E=+0.37 \mathrm{~V}$ vs. $\mathrm{SCE})^{[40]}$ was used as an internal standard. All electrochemical measurements were carried out under an atmospheric pressure of argon.

Laser Flash Photolysis Measurements. Femtosecond transient absorption spectroscopy experiments for PhCN solutions of $2-\mathbf{M}(\mathbf{M}=2 \mathrm{H}, \mathrm{Zn}$, and $\mathrm{Pd})$ were conducted using an ultrafast source: Integra-C (Quantronix Corp.), an optical parametric amplifier, TOPAS (Light Conversion Ltd.), and a commercially available optical detection system, Helios, provided by Ultrafast Systems LLC. The detailed information about femtosecond experiments is given in Supporting Information (SI).

Nanosecond time-resolved transient absorption measurements were carried out with the laser system provided by UNISOKU Co., Ltd. Measurements of nanosecond transient absorption spectra were performed according to the following procedure: A deaerated solution was excited by a Panther optical parametric oscillator pumped by a Nd:YAG laser (Continuum, SLII-10, 4-6 ns fwhm) at $\lambda=430 \mathrm{~nm}$. The photodynamics was monitored by continuous 
exposure to a xenon lamp (150 W) as a probe light and a photomultiplier tube (Hamamatsu 2949) as a detector.

ESR Spectroscopy. The ESR spectra were taken on a JEOL X-band spectrometer (JES-RE1XE) or Bruker EMXPlus 9.5/2.7 spectrometer with a quartz ESR tube. The simulation of ESR spectra was performed with a WinSim software.

The ESR spectrum of charge-separated state of 2-Pd in frozen $\mathrm{PhCN}$ was measured under photoirradiation with a high-pressure mercury lamp (USHIO LIGHTING USH-1005D) through a water filter focusing at the sample cell in the ESR cavity using a liquid helium cryostat before making the spectroscopic measurements at $4 \mathrm{~K}$. The $g$ value was calibrated using an $\mathrm{Mn}^{2+}$ marker.

Theoretical Calculations. Density functional theory (DFT) calculations were performed on a 32-processor QuantumCube with Gaussian03 (Revision C.02, Gaussian, Inc.). ${ }^{[41]}$ Geometry optimizations were carried out using the B3LYP function ${ }^{[42]}$ and $6-31 \mathrm{G}(\mathrm{d})$ basis set ${ }^{[43]}$ for $2-\mathrm{H}_{2}$ and $2-\mathrm{Zn}$, the LanL2DZ basis set $^{[44]}$ for $\mathrm{Pd}$ in 2-Pd. Graphical outputs of the computational results were generated with the Gauss View software program (ver. 3.09$)^{[45]}$ developed by Semichem, Inc.
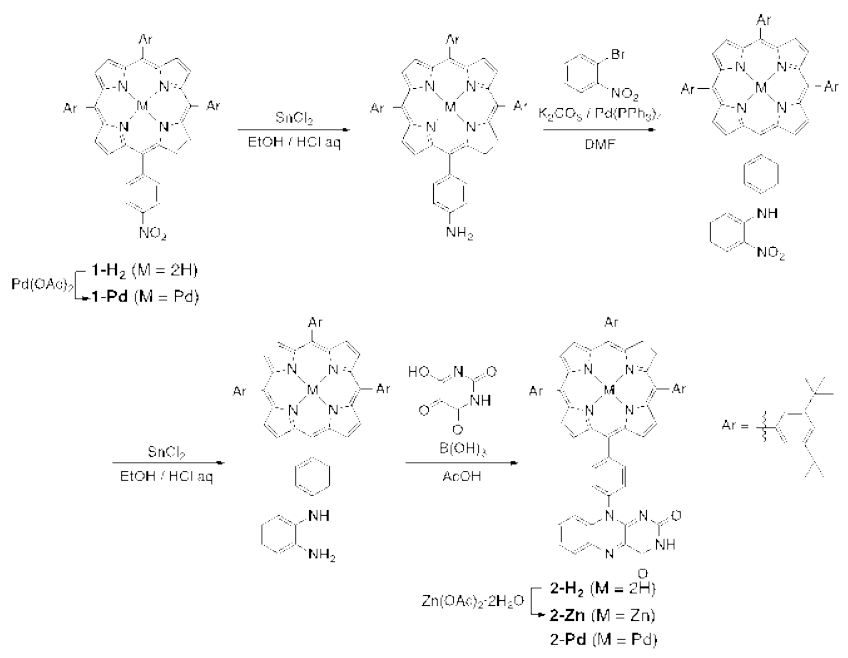

Scheme 1. Synthesis of porphyrin-flavin linked molecules.

\section{Results and Discussion}

Synthesis and Characterization of Porphyrin-Flavin Dyads (2-M, M = 2H, Zn, Pd). A precursor mononitroporphyrin $\left(\mathbf{1}-\mathbf{H}_{2}\right)$ was synthesized by condensation of meso-[3,5-di-(tertbutyl)phenyl]dipyrromethane with 3,5-di(tert-butyl)benzaldehyde and 4-nitrobenzaldehyde. ${ }^{[46,47]} \mathrm{A}$ target free-base porphyrin-flavin linked dyad $\left(\mathrm{H}_{2} \mathrm{Por}-\mathrm{Fl}, \mathbf{2}-\mathrm{H}_{2}\right)$ was prepared from $\mathbf{1}-\mathbf{H}_{\mathbf{2}}$ via a fourstep synthesis that is a general synthetic route for flavin derivatives; ${ }^{[48]}$ reduction of the nitro group, coupling with 2bromonitrobenzene, reduction of the nitro group, and formation of the isoalloxazine ring (Scheme 1). Insertion of the $\mathrm{Pd}^{2+}$ ion into the porphyrin core was made by the reaction of the mononitroporphyrin with $\mathrm{Pd}(\mathrm{OAc})_{2}$ in toluene. It should be noted that the $\mathrm{Pd}^{2+}$ insertion should be done prior to the formation of the flavin skeleton to avoid the strong complexation of the $\mathrm{Pd}^{2+}$ ion with the flavin moiety. ${ }^{[49]}$ Thus, the $\mathrm{Pd}^{\prime \prime}$ mononitroporphyrinate, 1$\mathbf{P d}$, was used as an intermediate to prepare a Pd-porphyrin-flavin dyad (2-Pd). As for the $Z n^{\prime \prime}$ complex of $\mathbf{2}-\mathbf{H}_{2}$, that is a $\mathbf{Z n}$ porphyrin-flavin dyad (2-Zn), the $\mathrm{Zn}^{\prime \prime}$ insertion was made straightforward by the reaction of $2-\mathrm{H}_{2}$ with $\mathrm{Zn}(\mathrm{OAc})_{2}$ in a $\mathrm{CH}_{2} \mathrm{Cl}_{2} / \mathrm{CH}_{3} \mathrm{OH}$ mixed solvent. In this case, the weak complexation of the $\mathrm{Zn}^{2+}$ ion with the flavin moiety allowed us to obtain the pure dyad by a standard purification procedure.

The formation of 2-M ( $M=2 \mathrm{H}, \mathrm{Zn}$, and $\mathrm{Pd})$ was confirmed by ${ }^{1} \mathrm{H}$ NMR and MALDI-TOF mass measurements. Peak assignments of the ${ }^{1} \mathrm{H}$ NMR spectra of 2-M are reported in the experimental section in Supporting Information (SI). The positivemode mass spectra gave peak clusters at $m / z=1165.6$ for $2-\mathbf{H}_{2}$, 1226.8 for $\mathbf{2 - Z n}$, and 1270.7 for $\mathbf{2 - P d}$, respectively. Their isotopic patterns were consistent with the simulation for positively ionized forms of their neutral dyads, allowing us to confirm the successful synthesis of the target dyads, as shown in Figure S1 in SI. Elemental analysis concreted the evidence of the formation of each Por-FI dyad.

Crystal Structure of 2-Pd. The structure of 2-Pd was explicitly established by X-ray crystallography (Figure 1). The porphyrin and the flavin moieties were covalently linked via a $p$-phenylene bridge. The porphyrin core is distorted with a ruffle conformation with the mean deviation of the 24 atoms of the porphyrin ring is $0.153 \AA$. On the other hand, the flavin moiety is almost planar with the mean deviation of $0.02 \AA$.

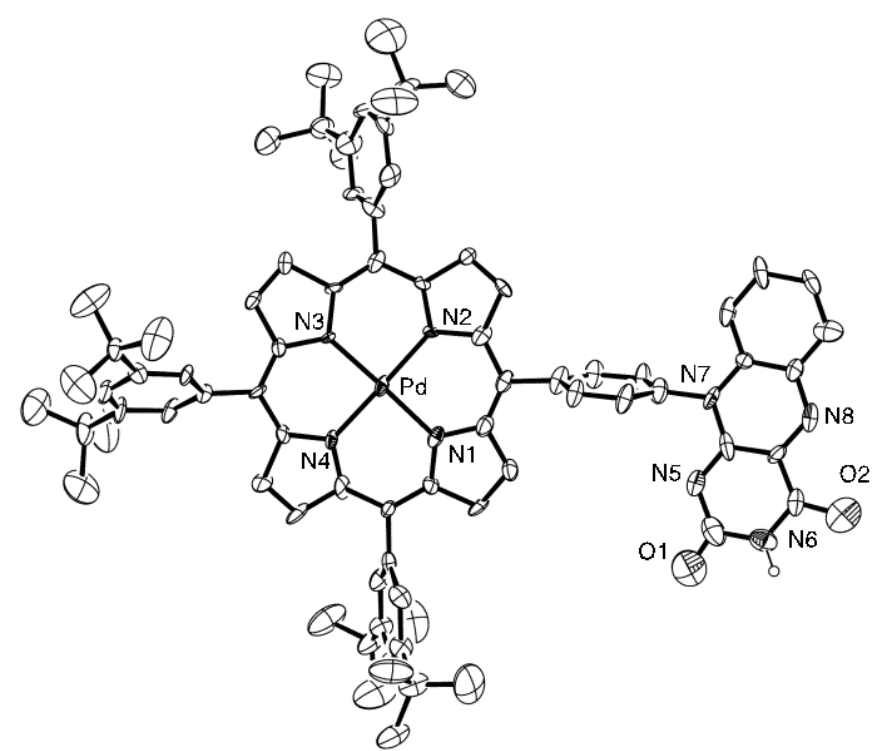

Figure 1. An ORTEP drawing of 2-Pd. The thermal ellipsoids are drawn with $50 \%$ probability. Hydrogen atoms are omitted for clarity, except that attached to $\mathrm{N} 6$ of the flavin moiety.

The dihedral angle between the porphyrin ring and the phenylene bridge is $62.5^{\circ}$, which corresponds to that of a freebase tetraphenylporphyrin $\left(64.8^{\circ}\right) .{ }^{[50]}$ The dihedral angle between the phenylene bridge and the flavin ring is similar to that between the porphyrin ring and the phenylene bridge to be $58.8^{\circ}$. In consequence, the porphyrin and the flavin moieties are almost co-planar and the dihedral angle between them is estimated to be $3.9^{\circ}$ (Figure S2 in SI).

In the crystal packing, the porphyrin moiety of 2-Pd is stacked with the flavin moiety of another vicinal molecule with the $\pi-\pi$ interaction (Figure S3 in $\mathrm{SI}$ ). The interplane distance between them is $3.44 \AA$. In addition, $\mathrm{CH} / \pi$ interaction between the porphyrin moiety and the phenylene ring of the vicinal molecule assisted the Por...FI interaction. The distance between the porphyrin plane and the ortho-carbon of the near side to the $\mathrm{FI}$ 
moiety is $3.30 \AA$. As a result of the formation of intermolecular Por...Fl interaction, 2-Pd forms a quasi-one-dimensional molecular wire in the crystal (Figure S3c in $\mathrm{SI}$ ).

Spectroscopic and Electrochemical Studies of PorphyrinFlavin Dyads. To investigate the interactions between porphyrin and flavin moieties, we performed UV-Vis spectroscopic measurements, electrochemical studies, and theoretical calculations. UV-Vis spectra of the porphyrin-flavin dyads $\left(\mathbf{2}-\mathbf{H}_{2}\right.$, 2-Zn, and 2-Pd) were measured in $\mathrm{PhCN}$ at room temperature (Figure $\mathrm{S} 4$ in $\mathrm{SI}$ ). Tetrakis(3,5-di-tert-butylphenyl)porphyrin and its $\mathrm{Zn}^{\prime \prime}$ and Pd" complexes (MPor, 3-M, M = 2H, Zn, and Pd) were employed as references. UV-Vis spectra of the reference compounds in $\mathrm{PhCN}$ are also displayed in Figure $\mathrm{S} 4(\mathrm{SI})$. The absorption maxima of $\mathbf{2 - M}$ and 3-M $(\mathbf{M}=2 \mathrm{H}, \mathrm{Zn}$, and $\mathrm{Pd})$ are listed in Table 1. Since extinction coefficients of flavins are much smaller than those of porphyrins, the absorption bands derived from the flavins moiety were not clearly observed and the porphyrin moieties were mainly observed in the range between 400 and $450 \mathrm{~nm}$. Comparing the absorption maxima of 2-M with those of reference porphyrins, no shifts were observed. In addition, no charge transfer (CT) bands were seen in their absorption spectra, indicating the absence of electronic interactions between the porphyrin and flavin moieties in the ground states.

Upon photoexcitation of $\mathbf{2}-\mathbf{H}_{2}$ at $427 \mathrm{~nm}$ in $\mathrm{PhCN}$, weaker fluorescence at 656 and $723 \mathrm{~nm}(\Phi=0.025)$ was observed relative to that of $3-\mathrm{H}_{2}(\Phi=0.091)$ (Figure $\mathrm{S} 5 \mathrm{a}$ in $\left.\mathrm{SI}\right)$. The fluorescence of $\mathbf{2 - Z n}\left(\lambda_{\max }=606\right.$ and $\left.656 \mathrm{~nm}\right)$ excited at $430 \mathrm{~nm}$ was almost quenched $(\Phi=0.003)$, compared to that of $3-\mathrm{Zn}(\Phi=$ 0.035). The emission maxima of fluorescence of $2-\mathbf{H}_{2}$ and $\mathbf{2 - Z n}$ also showed no shifts in comparison with those of their reference porphyrins, $\mathbf{3}-\mathbf{H}_{2}$ and $\mathbf{3}-\mathbf{Z n}$, respectively. Such remarkable quenching of fluorescence of the porphyrin moiety strongly suggests that energy or electron transfer from the porphyrin moiety of $\mathbf{2}-\mathbf{H}_{2}$ and $\mathbf{2}-\mathbf{Z n}$ to the flavin moiety is plausible (vide infra). 2-Pd exhibited very weak fluorescence similar to 3-Pd due

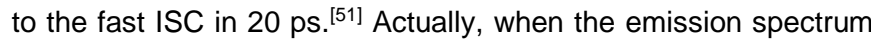
of 2-Pd was measured at $77 \mathrm{~K}$ in 2-methyl-THF under Ar with excitation at $525 \mathrm{~nm}$ (Figure S6b in SI), a sharp and intense band and a weak one were observed at 689 and $767 \mathrm{~nm}$, respectively. In the emission spectra of 3-Pd in 2-methyl-THF at $298 \mathrm{~K}$ under Ar with excitation at $525 \mathrm{~nm}$ (Figure S6a in SI), two bands similar to those observed for 2-Pd and a weak band were observed at 696, 763, and $607 \mathrm{~nm}$, respectively: The former two bands were mostly quenched, upon replacing the atmosphere from $\mathrm{Ar}$ to air, whereas the band at $607 \mathrm{~nm}$ maintained the intensity (red line in Figure S6a in SI). This indicates the former two emissions can be ascribed to the phosphorescence of the PdPor moiety and the latter is assigned to the fluorescence.

Electrochemical studies by using cyclic voltammetry (CV) and differential pulse voltammetry (DPV) were performed to determine redox potentials of 2-M $(\mathbf{M}=2 \mathrm{H}, \mathrm{Zn}, \mathrm{Pd})$ in deaerated $\mathrm{PhCN}$ containing $0.1 \mathrm{M} \mathrm{TBAPF}_{6}$ as an electrolyte at room temperature. The CVs of 2-M ( $\mathbf{M}=2 \mathrm{H}, \mathrm{Zn}, \mathrm{Pd})$ exhibited reversible redox waves in the range between +0.7 and $+1.1 \mathrm{~V}$ (vs. SCE), which were assigned to those of the first oxidation processes of the porphyrin moieties. The half-wave potentials were determined to be $E_{1 / 2}=+1.03 \vee$ for $\mathbf{2}-\mathbf{H}_{2},+0.69 \vee$ for $\mathbf{2}-\mathbf{Z n}$, and $+1.03 \vee$ for $\mathbf{2}-\mathbf{P d}$
Table 1. Absorption maxima of 2-M and the reference porphyrins (3-M).

\begin{tabular}{ccc}
\hline & Soret band, $\mathrm{nm}$ & Q band, nm \\
\hline 2-H & 424 & $518,555,594,649$ \\
3-H2 & 424 & $519,554,592,650$ \\
2-Zn & 432 & 562,604 \\
3-Zn & 430 & 559,600 \\
2-Pd & 421 & 526,559 \\
3-Pd & 421 & 526,559 \\
\hline
\end{tabular}

Table 2. The first oxidation and reduction potentials of 2-M and their references (3-M) in $\mathrm{PhCN}$.

\begin{tabular}{|c|c|c|}
\hline & $E_{\text {ox }}$, V vs. SCE ${ }^{a}$ & $E_{\text {red }}, V$ vs. SCE ${ }^{b}$ \\
\hline $2-\mathrm{H}_{2}$ & +1.03 & -0.69 \\
\hline $2-Z n$ & +0.69 & -0.79 \\
\hline 2-Pd & +1.03 & -0.77 \\
\hline 2-Pd $\cdots \mathrm{Sc}^{3+}$ & +1.06 & +0.11 \\
\hline 2-Pd $\cdots 2 \mathrm{Sc}^{3+}$ & +1.02 & +0.21 \\
\hline 3- $\mathrm{H}_{2}$ & $+0.95^{c}$ & \\
\hline $3-Z n$ & +0.64 & \\
\hline 3-Pd & +0.96 & \\
\hline DecFI & & -0.74 \\
\hline
\end{tabular}

a Half-wave potentials determined by CV. ${ }^{b}$ Peak potentials determined by DPV. ${ }^{c}$ Taken from ref. 52 .

(Figure $\mathrm{S} 7$ in $\mathrm{SI}$ ). The values were similar to the oxidation potentials of the reference porphyrins (Table 2). On the other hand, irreversible redox waves were observed in the range from 0.7 to $-0.8 \mathrm{~V}$, which were also similar to the reduction potential of $10-N$-decylisoalloxazine (DecFl; $E_{\text {red }}=-0.74 \mathrm{~V}$ vs. SCE). The reduction potentials of 2-M were determined by DPV to be -0.69 $\mathrm{V}$ for $\mathbf{2}-\mathbf{H}_{2},-0.79 \mathrm{~V}$ for $\mathbf{2}-\mathbf{Z n}$, and $-0.77 \mathrm{~V}$ for $\mathbf{2}-\mathbf{P d}$. Thus, it was found that the redox potential of each moiety was affected by the metal center of the porphyrin moiety, despite no interaction between the porphyrin and flavin moieties before the redox process.

To gain further information on the electronic structures of porphyrin-flavin dyads, we performed theoretical calculations. The optimized structure of $\mathbf{2}-\mathrm{H}_{2}$ and the HOMO and LUMO distributions, calculated by DFT methods at the B3LYP/6-31G(d) level of theory, are shown in Figure S8a (SI). The HOMO was localized on the porphyrin moiety, whereas the LUMO was completely localized on the flavin moiety without leaking. Similarly, the HOMO and LUMO of 2-Zn and 2-Pd were separated on the porphyrin and the flavin moieties, respectively (Figure S8b and c in SI, respectively). These results suggest that the photoinduced ET occurs from the porphyrin moiety to the flavin moiety upon photoexcitation of each Por-Fl dyad. 
The Effect of Binding of Metal lons to the Flavin Moiety on the Redox Potentials. We performed UV-vis titration to estimate the binding constants of four kinds of metal ions $\left(\mathrm{Sc}^{3+}, \mathrm{Y}^{3+}, \mathrm{Mg}^{2+}\right.$ and $\mathrm{Zn}^{2+}$ ) to the flavin moiety. ${ }^{[39]}$ Since the absorption of porphyrin moiety is too large to determine the binding constant from the change of the absorbance of the flavin moiety, 10- $N$-decylisoalloxazine (DecFl) was used instead of the Por-Fl dyads. Upon adding $\mathrm{Sc}(\mathrm{OTf})_{3}$ to the PhCN solution of DecFl $(100 \mu \mathrm{M})$, a two-step spectral change was observed as depicted in Figure 2. In the course of titration in $\mathrm{PhCN}$, the $\mathrm{Sc}^{3+}$ ion should bear OTf ions in the light of the strongly hard-acid character that favors the binding of OTf as a hard base rather than that of PhCN as a soft base. ${ }^{\left[{ }^{3}\right]}$ In the first step, the absorption band at $439 \mathrm{~nm}$ decreased simultaneously with increasing the absorption band at $364 \mathrm{~nm}$, exhibiting an isosbestic point at $409 \mathrm{~nm}$ (Figure 2a). In the second step, concurrently with increasing the absorption band at $422 \mathrm{~nm}$, the absorption band at $364 \mathrm{~nm}$ increased, exhibiting an isosbestic point at $461 \mathrm{~nm}$ (Figure 2b). The absorption maxima at 439,365 and $422 \mathrm{~nm}$ correspond to the absorption of DecFI, the singly $\mathrm{Sc}^{3+}$ ion-bound $\mathrm{DecFI}\left(\mathrm{DecFl} \cdots \mathrm{Sc}^{3+}\right.$ ), and the doubly $\mathrm{Sc}^{3+}$ ion- bound DecFl (DecFl $\cdots 2 \mathrm{Sc}^{3+}$ ), respectively (Scheme 2). a)

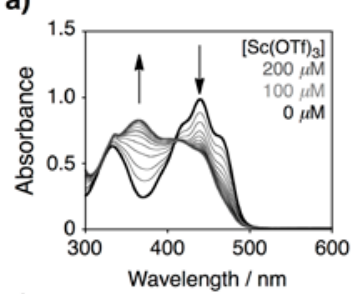

c)

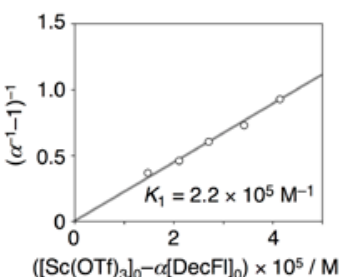

b)

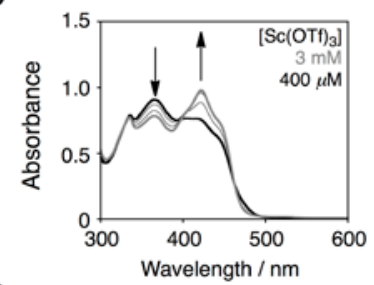

d)

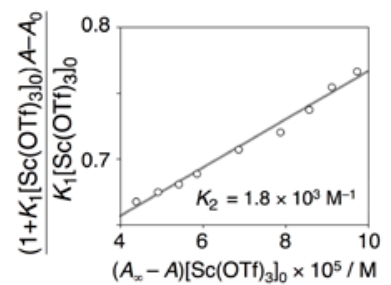

Figure 2. Absorption spectral change in the course of the titration of DecFI (100 $\mu \mathrm{M})$ with $\mathrm{Sc}(\mathrm{OTf})_{3}$ in $\mathrm{PhCN}$ at room temperature. a) 0-200 $\mu \mathrm{M}$, b) 0.4-3 mM. c) Plots for the first equilibrium of complexation of DecFl with $\mathrm{Sc}(\mathrm{OTf})_{3}$ in $\mathrm{PhCN}$ at room temperature monitored at $365 \mathrm{~nm}$. d) Plots for the second equilibrium of complexation of $\mathrm{DecFl} \cdots \mathrm{Sc}^{3+}$ with $\mathrm{Sc}(\mathrm{OTf})_{3}$ in $\mathrm{PhCN}$ at room temperature monitored at $422 \mathrm{~nm}$.

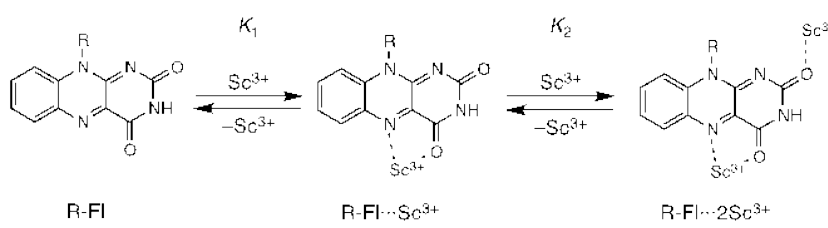

Scheme 2. Plausible binding modes of $\mathrm{Sc}^{3+}$ ions in the complexation with a flavin derivative.

Titration experiments were also performed using the other three metal salts $\left(\mathrm{Y}(\mathrm{OTf})_{3}, \mathrm{Mg}\left(\mathrm{ClO}_{4}\right)_{2}\right.$ and $\left.\mathrm{Zn}(\mathrm{OTf})_{2}\right)$ (Figure S9 in $\mathrm{SI})$. As well as the case of titration with $\mathrm{Sc}(\mathrm{OTf})_{3}$, the absorption bands of DecFl at $439 \mathrm{~nm}$ decayed upon addition of solutions of the other three metal salts. However, the spectral changes for titration with $\mathrm{Y}^{3+}, \mathrm{Mg}^{2+}$, or $\mathrm{Zn}^{2+}$ ions, appeared as a one-step process and the subsequent changes as observed in the titration with $\mathrm{Sc}(\mathrm{OTf})_{3}$ were not observed. This indicates that the most strongly Lewis-acidic $\mathrm{Sc}^{3+}$ ion ${ }^{[54]}$ only can doubly bind to DecFl, whereas no second binding of less Lewis-acidic ions such as $\mathrm{Y}^{3+}$ ion occurred. The isosbestic points of the spectral changes were observed at $433 \mathrm{~nm}$ for $\mathrm{Y}(\mathrm{OTf})_{3}, 493 \mathrm{~nm}$ for $\mathrm{Mg}\left(\mathrm{ClO}_{4}\right)_{2}$, and 480 $\mathrm{nm}$ for $\mathrm{Zn}(\mathrm{OTf})_{2}$, respectively. Absorbance change in the course of the titration was analyzed by using Equations (1) ${ }^{[55]}$ and (2) ${ }^{[56]}$ to determine the first and the second binding constants, $K_{1}$ and $K_{2}$, respectively, as defined by Equations (3) and (4), respectively.

$$
\begin{aligned}
& \left(\alpha^{-1}-1\right)^{-1}=K_{1}\left(\left[\mathrm{Sc}(\mathrm{OTf})_{3}\right]_{0}-\alpha[\operatorname{DecFl}]_{0}\right), \alpha=\frac{\left(A-A_{0}\right)}{\left(A_{\infty}-A_{0}\right)} \\
& \frac{\left\{1+K_{1}\left[\mathrm{Sc}(\mathrm{OTf})_{3}\right]\right\} A-A_{0}}{K_{1}\left[\mathrm{Sc}(\mathrm{OTf})_{3}\right]}=K_{2}\left(A_{\infty}^{\prime}-A_{0}\right)\left[\operatorname{Sc}(\mathrm{OTf})_{3}\right]+A_{0} \\
& K_{1}=\frac{\left[\mathrm{DecFl} \cdots \mathrm{Sc}^{3+}\right]}{[\mathrm{DeclFl}]\left[\mathrm{Sc}(\mathrm{OTf})_{3}\right]}
\end{aligned}
$$

$$
K_{2}=\frac{\left[\mathrm{DecFl} \cdots 2 \mathrm{Sc}^{3+}\right]}{\left[\mathrm{DeclFl} \cdots \mathrm{Sc}^{3+}\right]\left[\mathrm{Sc}(\mathrm{OTf})_{3}\right]}
$$

Herein, $A_{0}, A_{\infty}$, and $A_{\infty}^{\prime}$ are the initial absorbance, the final absorbance for the first and second binding of the metal ions, respectively. On the basis of the change in absorbance at $365 \mathrm{~nm}$ for $\mathrm{Sc}^{3+}, 362 \mathrm{~nm}$ for $\mathrm{Y}^{3+}, \mathrm{Mg}^{2+}$ and $\mathrm{Zn}^{2+}$, the $K_{1}$ values were determined to be $2.2 \times 10^{5} \mathrm{M}^{-1}$ for $\mathrm{Sc}^{3+}, 1.2 \times 10^{3} \mathrm{M}^{-1}$ for $\mathrm{Y}^{3+}, 3.2$ $\times 10^{2} \mathrm{M}^{-1}$ for $\mathrm{Mg}^{2+}, 6.1 \times 10^{2} \mathrm{M}^{-1}$ for $\mathrm{Zn}^{2+}$, respectively (Figure S9 and Table S1 in SI). The analysis of absorbance change at 422 $\mathrm{nm}$ for the titration of $\mathrm{Sc}^{3+}$ ion afforded $K_{2}$ as $1.8 \times 10^{3} \mathrm{M}^{-1}$. The intercept of the plot on the basis of Equation (2) afforded the absorbance $\left(A_{0}{ }^{\prime}\right)$ of the 1:1 complex of flavin with $\mathrm{Sc}^{3+}$ ion (Figure 2d).

The protonated form of the $\mathbf{2}-\mathbf{H}_{2}$ dyad, represented as $\left[\mathrm{H}_{4} \mathrm{Por}^{2+}-\mathrm{Fl}\right]$, was obtained by adding $\mathrm{Sc}(\mathrm{OTf})_{3}$ to the $\mathrm{PhCN}$ solution of $\mathbf{2}-\mathbf{H}_{2}$ and $\mathbf{2}-\mathbf{Z n}$. The protonation occurred probably due to proton release from residual water in $\mathrm{PhCN}$ through its interaction with the strongly Lewis-acidic $\mathrm{Sc}^{3+}$ ion. In sharp contrast, 2-Pd was stable without demetallation upon addition of $\mathrm{Sc}(\mathrm{OTf})_{3}$ in PhCN. Therefore, spectroscopic and electrochemical studies on the effect of the metal ions were performed only on 2Pd.

Phosphorescence spectra of 2-Pd were measured during the titration with $\mathrm{Sc}(\mathrm{OTf})_{3}$ in the $\mathrm{PhCN}$ solution (Figure $\mathrm{S} 10$ in $\mathrm{SI}$ ). The addition of the $\mathrm{Sc}^{3+}$ ion caused decrease in the intensity of the phosphorescence of 2-Pd, indicating that photoinduced ET from the PdPor moiety to the FI moiety was enhanced by the $\mathrm{Sc}^{3+}$ binding at the $\mathrm{Fl}$ moiety (vide infra).

Figure 3 shows the results of DPV measurements on 2-Pd in deaerated $\mathrm{PhCN}$ under $\mathrm{Ar}$ atmosphere in the course of addition of $\mathrm{Sc}(\mathrm{OTf})_{3}$. Since the redox waves of $\mathrm{Sc}^{3+}$-bound 2-Pd species were quasi-reversible in the $\mathrm{CV}$ measurements, the reduction potentials were determined by DPV measurements. No change was observed for the oxidation potential or the reduction potential of the porphyrin moiety. For instance, the reduction potential at $1.39 \mathrm{~V}$ remained the same in the presence of various concentrations of $\mathrm{Sc}^{3+}$ as shown in Figure 3. This observation 
a)

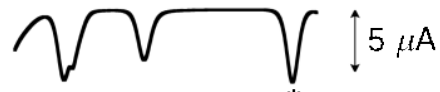

b)

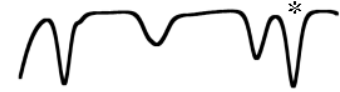

c)<smiles>CCCCCCCCC1CCCC1C</smiles>

d)<smiles>CCCCCCCCCCCCCCCCC</smiles>

e)<smiles>CCCCCCCCCCCCCCCCCC</smiles>

f)

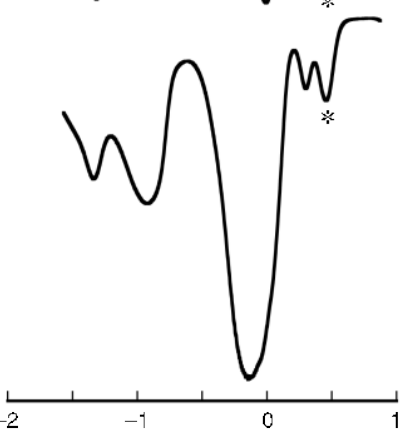

\section{E / V vs SCE}

Figure 3. DPVs of 2-Pd (1.0 mM) in the presence of 0 eq a), 0.5 eq b), 1.0 eq c), 1.5 eq d), 2.0 eq e) and 20 eq f) of $\mathrm{Sc}^{3+}$ ion in PhCN containing $\operatorname{TBAPF}_{6}(0.1 \mathrm{M})$ at room temperature.

indicates that $\mathrm{Sc}^{3+}$ does not bind to the porphyrin moiety. In sharp contrast, a peak due to the reduction of the FI moiety of 2-Pd observed at $-0.77 \mathrm{~V}$ in the absence of $\mathrm{Sc}^{3+}$ was gradually degraded with adding $\mathrm{Sc}(\mathrm{OTf})_{3}$ in portions up to 1 eq relative to 2Pd, and instead a new reduction DPV peak was observed at $+0.11 \mathrm{~V}$. In the titration experiments, the $\mathrm{Sc}^{3+}$-free and $\mathrm{Sc}^{3+}$. bound 2-Pd always exhibited two different reduction waves, which never merged into one wave, and the electrical current for each process gradually changed as increasing the amount of the $\mathrm{Sc}^{3+}$ ion added to the solution (Figure $\mathrm{S} 11$ in $\mathrm{SI}$ ). This indicates that the $\mathrm{Sc}^{3+}$-binding is very strong and the rate of the exchange reaction between the $\mathrm{Sc}^{3+}$-free and $\mathrm{Sc}^{3+}$-bound 2-Pd molecules is slow relative to that of electron transfer on the electrode surface. The large positive shift should be derived from the $\mathrm{Sc}^{3+}$ binding to the 4a-oxygen and the 5-nitrogen (Scheme 2). When the amount of $\mathrm{Sc}(\mathrm{OTf})_{3}$ increased to 2 eq relative to 2-Pd, new large and small peaks were observed at -0.30 and $+0.21 \mathrm{~V}$, respectively, in addition to the reduction wave at $+0.11 \mathrm{~V}$, ascribable to the $1 \mathrm{e}^{-}-$ reduction of one-Sc ${ }^{3+}$-bound $\mathrm{Fl}$ moiety in 1-Pd. The new peak at $0.30 \mathrm{~V}$ may result from the catalytic reduction of proton, which is produced by the $\mathrm{Sc}^{3+}$ ion from the residual water in $\mathrm{PhCN}$. Upon increasing the amount of the $\mathrm{Sc}^{3+}$ ion to $20 \mathrm{eq}$, the wave at +0.21 $\mathrm{V}$ became dominant and that at $+0.11 \mathrm{~V}$ ascribable to the $\mathrm{Sc}^{3+}$. bound $\mathrm{Fl}$ reduction disappeared. Therefore, the wave at $+0.21 \mathrm{~V}$ can be assigned to the reduction of the $\mathrm{Fl}$ moiety bound to two $\mathrm{Sc}^{3+}$ ions $\left(\mathbf{2}-\mathbf{P d} \cdots 2 \mathrm{Sc}^{3+}\right)$.

To investigate the electronic characteristics of $1 \mathrm{e}^{-}$-reduced species of 2-Pd bound to two $\mathrm{Sc}^{3+}$ ions, we measured an ESR spectrum of a reduction product of 2-Pd with use of 1 eq of decamethylferrocene $\left(\mathrm{Fc}^{\star}\right)$ in $\mathrm{PhCN}$ at $298 \mathrm{~K}$ in the presence of $\mathrm{Sc}(\mathrm{OTf})_{3}$ (Figure $\mathrm{S} 12$ in $\mathrm{SI}$ ). A signal was observed at $g=2.005$ and the hyperfine splitting was analyzed by computer simulation (red line in Figure $\mathrm{S} 12$ in $\mathrm{SI}$ ) on the basis of DFT calculations (Figure $\mathrm{S} 13$ in $\mathrm{SI}$ ). DFT calculations on the $1 \mathrm{e}^{-}$-reduced 10phenyl-flavin ( $\mathrm{PhFl}$ ) revealed that the spin densities were mainly localized on 5-N, 10-N, 6-C and 9a-C (Figure S14 in SI). Based on the density map obtained from the DFT calculations, we simulated the ESR spectrum to confirm that two nitrogens (5-N and $10-\mathrm{N}$ ) and three hydrogens bonded to $6-\mathrm{C}, 8-\mathrm{C}$ and $9-\mathrm{C}$ strongly contributed to the hyperfine splitting. ${ }^{[57]}$ The agreement of the simulated spectrum based on the DFT calculations with the experimental result strongly suggests that two $\mathrm{Sc}^{3+}$ ions bind to the flavin moiety of 2-Pd.

Photodynamics of Intramolecular Photoinduced Electron Transfer in the Absence of $\mathbf{S c}^{3+}$. The energy levels of the singlet and the triplet excited states $\left(E_{\mathrm{S}}\right.$ and $\left.E_{\mathrm{T}}\right)$ were determined from the absorption, fluorescence and phosphorescence maxima using Equations (5) and (6), respectively. Here, $\lambda_{\mathrm{Abs}}$ is the longest wavelength of the absorption maxima, $\lambda_{\mathrm{Fl}}$ is the longest wavelength of the fluorescence maxima, and $\lambda_{\text {Phos }}$ is the shortest wavelength of the phosphorescence maxima. The energies of the charge-separated state $\left(E_{\mathrm{CS}}\right)$ were determined on the basis of the one-electron oxidation potentials of the porphyrin moiety and the one-electron reduction potentials of the Fl moiety in 2-M using

$$
\begin{aligned}
& E_{\mathrm{S}}=\frac{\left(\frac{1240}{\lambda_{\mathrm{Abs}}}+\frac{1240}{\lambda_{\mathrm{Fl}}}\right)}{2} \\
& E_{\mathrm{T}}=\frac{1240}{\lambda_{\mathrm{Phos}}} \\
& E_{\mathrm{CS}}=e\left(E_{\mathrm{ox}}-E_{\mathrm{red}}\right)
\end{aligned}
$$

Equation (7). The $E_{\mathrm{S}}, E_{\mathrm{T}}$ and $E_{\mathrm{CS}}$ values are summarized in Table 3.

Table 3. Energies of the singlet, triplet and charge-separated states of $2-\mathbf{M}(M=2 H, Z n, P d)$.

\begin{tabular}{c|ccc}
\hline & $E_{\mathrm{S}}, \mathrm{eV}$ & $E_{\mathrm{T}}, \mathrm{eV}$ & $E_{\mathrm{CS}, \mathrm{eV}}$ \\
\hline 2-H & 1.90 & $1.44^{a}$ & 1.72 \\
2-Zn & 2.06 & $1.57^{a}$ & 1.48 \\
2-Pd & 2.13 & $1.62^{b}$ & 1.80 \\
2-Pd $\cdots \mathrm{Sc}^{3+}$ & - & - & 0.95 \\
2-Pd$\cdots 2 \mathrm{Sc}^{3+}$ & - & - & 0.81 \\
\hline
\end{tabular}

${ }^{a}$ The values were determined from the phosphorescence maxima of free-base and zinc tetraphenylporphyrin referred in the literature (ref. 57). ${ }^{b}$ Phosphorescence maximum of 2-Pd (696 nm, excitation at $524 \mathrm{~nm}$ in 2-methyl-THF at $77 \mathrm{~K}$ ) was used for calculation.

Femtosecond (fs) laser flash photolysis was conducted in deaerated $\mathrm{PhCN}$ to elucidate the photodynamics of a series of Por-Fl dyads. After laser illumination at $430 \mathrm{~nm}$ to a deaerated $\mathrm{PhCN}$ solution of $\mathbf{2}-\mathbf{H}_{2}$, the transient absorption spectrum was observed at 3 ps with four breaching bands, which correspond to 
the $\mathrm{Q}$ band of the porphyrin moiety at $514,555,600$ and $650 \mathrm{~nm}$ as shown in Figure $4 \mathrm{a}$. The initial excited state of $\mathbf{2}-\mathbf{H}_{2}$ should be the singlet excited state of the porphyrin component, ${ }^{1}\left[\mathrm{H}_{2} \mathrm{Por}\right]^{*}-\mathrm{FI}$. The absorption due to a free-base porphyrin radical cation, $\mathrm{H}_{2} \mathrm{Por}^{\circ+}$, has been reported to be observed as a broad band in the range of $600-700 \mathrm{~nm}^{\left[{ }^{[58]}\right.}$ As can be seen in Figure $4 \mathrm{a}, \mathbf{2}-\mathbf{H}_{2}$ also exhibited a broad absorption band in the range, suggesting the formation of a $\left[\mathrm{H}_{2} \mathrm{Por}^{++}\right]$moiety. On the other hand, at $300 \mathrm{ps}$, a bleaching at $455 \mathrm{~nm}$ increased (Figure 4a). Since the flavin moiety exhibits an absorption at $450 \mathrm{~nm}$, the bleaching at $455 \mathrm{~nm}$ can be ascribed to the disappearance of the absorption to form the $\mathrm{Fl}^{0^{--}}$species. ${ }^{[24]}$ Together with the formation of the $\left[\mathrm{H}_{2} \mathrm{Por}^{*+}\right]$ segment in 2- $\mathrm{H}_{2}$, ET from the porphyrin moiety to the flavin moiety should occur to form the CS state of $2-\mathrm{H}_{2}, \mathrm{H}_{2} \mathrm{Por}^{\circ+}-\mathrm{Fl}^{-0}$. The absorption maximum of the reduced flavin moiety is out of the range of our measurements (cf. $\lambda_{\max }=370 \mathrm{~nm}$ for MeFl' ${ }^{-}$), ${ }^{[24]}$ and thus, no transient positive absorption band derived from the $\mathrm{Fl}^{-}-$moiety was observed. The nanosecond (ns) transient absorption spectrum of $\mathbf{2}-\mathbf{H}_{2}$ at $10 \mathrm{~ms}$ after photoexcitation and the reference $3-\mathrm{H}_{2}$ at $20 \mathrm{~ms}$ are shown in Figures $4 \mathrm{c}$ and $4 \mathrm{~d}$, respectively. There was no bleaching due to the absorption of the flavin moiety at around $450 \mathrm{~nm}$, and the transient absorption spectrum of $\mathbf{3}-\mathrm{H}_{2}$ was quite similar to that of the triplet excited state of $3-\mathrm{H}_{2}\left({ }^{3} \mathrm{H}_{2} \mathrm{Por}^{*}\right)$ as shown in Figure $4 \mathrm{~d}$. Therefore, we conclude that the final stage of the photochemical events of $\mathbf{2}-\mathrm{H}_{2}$ is the formation of ${ }^{3}\left[\mathrm{H}_{2} \mathrm{Por}\right]^{*}-\mathrm{Fl}$, which returns to the ground state. Bi-exponential curve fitting of the decay of the absorbance at 630 $\mathrm{nm}$ allowed us to determine the rate constants for the CS process from ${ }^{1}\left[\mathrm{H}_{2} \mathrm{Por}\right]^{\star}-\mathrm{Fl}$ to $\mathrm{H}_{2} \mathrm{Por}^{*+}$ and the $\mathrm{CR}$ process to form ${ }^{3}\left[\mathrm{H}_{2} \mathrm{Por}\right]^{{ }^{*}}$ Fl. The rate constants of the forward and backward electron transfer in 2- $\mathrm{H}_{2}$ were determined to be $1.2 \times 10^{10} \mathrm{~s}^{-1}$ and $1.2 \times$ $10^{9} \mathrm{~s}^{-1}$, respectively (Figure $4 \mathrm{~b}$ ).

Time-resolved fs-transient absorption spectra of $\mathbf{2 - Z n}$ at $1.5,3$, 15 , and 100 ps are shown in Figure $5 \mathrm{a}$. The transient absorption maximum at $630 \mathrm{~nm}$ observed at 1.5 and 3 ps was shifted to 621 $\mathrm{nm}$ at $15 \mathrm{ps}$. At the same time, a new bleaching at $452 \mathrm{~nm}$, assigned to the absorption of the flavin moiety, was observed. ${ }^{[24]}$ Moreover, the shape of the observed spectra is similar to the difference spectrum of a solution containing $\mathrm{ZnPor}^{\circ+}-\mathrm{Fl}$ generated by chemical oxidation by $\left[\mathrm{Ru}^{\prime \prime \prime}(\mathrm{bpy})_{3}\right]\left(\mathrm{PF}_{6}\right)_{3}$ (bpy = 2,2'-bipyridine), showing the absorption maximum at $625 \mathrm{~nm}$ (Figure S15 in SI). After 100 ps, all absorption and bleaching almost vanished, and nothing was observed by ns laser flash photolysis. These results indicate that formation of the singlet excited state of $\mathbf{2 - Z n}$ $\left({ }^{1}[\mathrm{ZnPor}]^{\star}-\mathrm{Fl}\right)$ by photoexcitation results in electron transfer from ${ }^{1} \mathrm{ZnP}^{*}$ to $\mathrm{Fl}$ to generate the singlet CS state of $2-\mathrm{Zn}\left(\mathrm{ZnPor}^{++}-\mathrm{Fl}^{\circ-}\right)$, followed by the charge recombination $(\mathrm{CR})$ of $\mathrm{ZnPor}^{++}-\mathrm{Fl} \mathbf{0}^{--}$to recover the ground state. To confirm this, we analyzed the time profiles of absorptions at 548 and $630 \mathrm{~nm}$. Since an isosbestic point was observed at $548 \mathrm{~nm}$ in the spectral change from 2-Zn to $\mathrm{ZnPor}^{++}-\mathrm{Fl}(\triangle \mathrm{Abs}=0$ in Figure S15 in SI), we could determine the rate constant of the formation of the CS state from ${ }^{1}[\mathrm{ZnPor}]^{*}-$ $\mathrm{Fl}$ by using the time profile at the isosbestic point without contribution of the absorbance of the CS state. The rate constant of the formation of the CS state from ${ }^{1}[\mathrm{ZnPor}]^{*}-\mathrm{Fl}$ was determined to be $1.6 \times 10^{11} \mathrm{~s}^{-1}$ by using a single-exponential curve for the absorbance change at $548 \mathrm{~nm}$ (Figure $5 \mathrm{~b}$, upper). Based on this value, time-course of the absorbance at $630 \mathrm{~nm}$ was analyzed by using a biexponential curve to obtain the CR rate constant of 6.5 $\times 10^{10} \mathrm{~s}^{-1}$ (Figure 5b, lower). a)

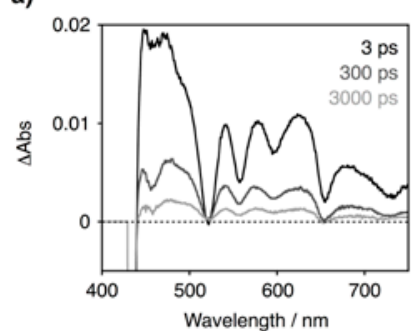

c)

b)

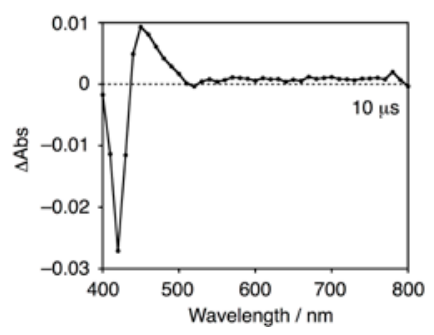

d)
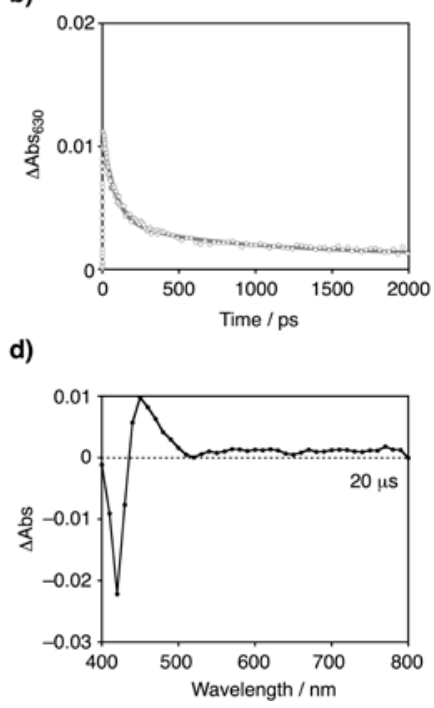

Figure 4. a) Femtosecond transient absorption spectra of $2-\mathrm{H}_{2}(7 \mu \mathrm{M})$ in deaerated $\mathrm{PhCN}$ at room temperature taken at $3 \mathrm{ps}, 300 \mathrm{ps}$, and $3000 \mathrm{ps}$. b) Time profile of the absorption at $630 \mathrm{~nm}$ for (a). Solid lines are the least-squares fitting curves using biexponential decay functions. c) Nanosecond transient absorption spectrum of $2-\mathrm{H}_{2}(1 \mu \mathrm{M})$ in deaerated $\mathrm{PhCN}$ at room temperature at $10 \mu \mathrm{s}$. d) Nanosecond transient absorption spectrum of the reference free-base porphyrin $\left(3-\mathrm{H}_{2}\right)$ in deaerated $\mathrm{PhCN}$ at room temperature at $20 \mu \mathrm{s}$.

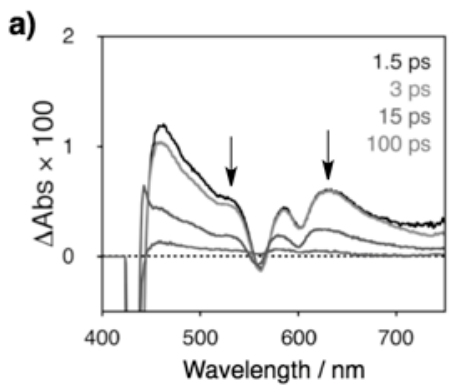

b)

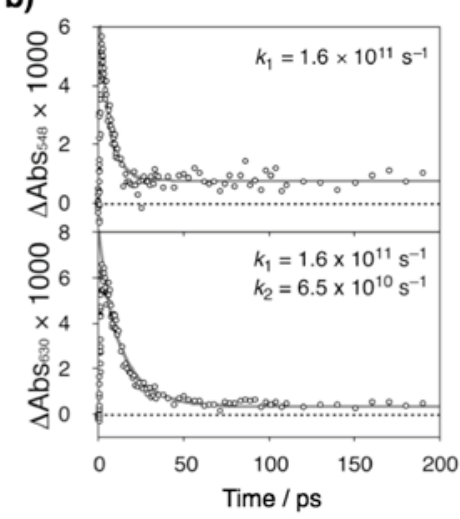

Figure 5. a) Femtosecond transient absorption spectra of 2-Zn (5 $\mu \mathrm{M})$ excited at $430 \mathrm{~nm}$ in deaerated $\mathrm{PhCN}$ at room temperature taken at $1.5 \mathrm{ps}, 3 \mathrm{ps}, 15 \mathrm{ps}$ and 100 ps. b) Time profiles of the absorptions at $548 \mathrm{~nm}$ (top) and $630 \mathrm{~nm}$ (bottom). Solid lines are the least-square fitting curves by single-exponential $(548 \mathrm{~nm})$ and bi-exponential $(630 \mathrm{~nm})$ decay.

The transient absorption spectrum observed in the fs-laser flash photolysis of 2-Pd $(10 \mu \mathrm{M})$ in deaerated $\mathrm{PhCN}$ at 1 ps after photoexcitation at $390 \mathrm{~nm}$ exhibited three absorption bands at 500,590 and $640 \mathrm{~nm}$, accompanied by bleaching bands at 540 and $560 \mathrm{~nm}$ (Figure 6a), which were assigned to the Q-bands of the PdPor moiety (vide supra). The former two bands (500 and 

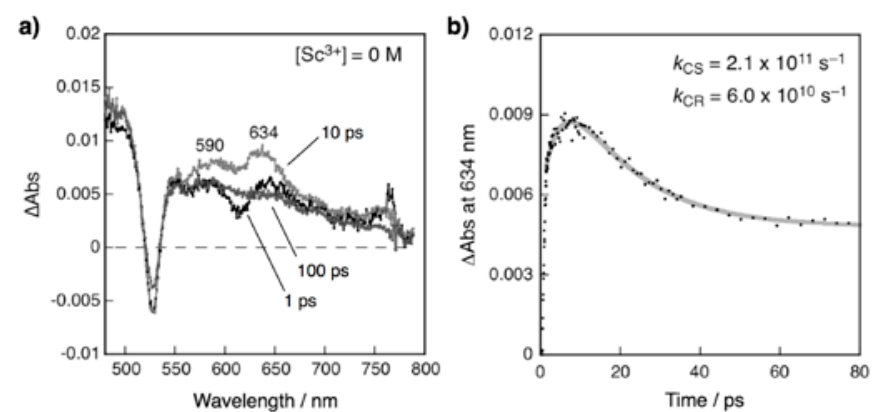

Figure 6. a) Femtosecond transient absorption spectra of 2-Pd (10 $\mu \mathrm{M})$ excited at $390 \mathrm{~nm}$ in deaerated $\mathrm{PhCN}$ taken at 1.0, 10, and $100 \mathrm{ps}$. b) Time profile of the absorption at $634 \mathrm{~nm}$.

$590 \mathrm{~nm})$ were assigned to that derived from the triplet excited state of the PdPor moiety ( $\left.{ }^{3}[\mathrm{PdPor}]^{\star}-\mathrm{Fl}\right)$ and the latter $(640 \mathrm{~nm})$ was to that of the singlet excited state $\left({ }^{1}[\mathrm{PdPor}]^{\star}\right.$-FI) from the transient absorption spectra of the reference compound (3-Pd) in deaerated $\mathrm{PhCN}$ (Figure $\mathrm{S} 16 \mathrm{a}$ in $\mathrm{SI}$ ). At $5.8 \mathrm{ps}$, a new and relatively sharp absorption band appeared at $634 \mathrm{~nm}$. Since the $1 \mathrm{e}^{-}$-oxidized species of $\mathbf{3 - P d}$ by using an aminyl radical as an oxidant displayed the relatively sharp absorption band at $627 \mathrm{~nm}$ (Figure S17 in SI), the band observed at $634 \mathrm{~nm}$ can be ascribed to that of the $1 \mathrm{e}^{-}$-oxidized PdPor moiety in the CS state of 2-Pd $\left(\right.$ PdPor $\left.^{\circ+}-\mathrm{Fl}^{--}\right)$. The time profile for the absorbance at $634 \mathrm{~nm}$ in the transient absorption spectra up to 6 ps was analyzed by single-exponential curve fitting to afford the rate constant of $2.1 \times$ $10^{11} \mathrm{~s}^{-1}$. Thus, we ascribed this rate constant to that of the intramolecular electron transfer to form the singlet CS state. In the transient absorption spectrum at 60 ps, only the broad absorption of ${ }^{3}[\mathrm{PdPor}]^{\star}-\mathrm{Fl}$ was observed with the bleach derived from the Q-bands of the PdPor moiety and the spectrum survived at 3000 ps (Figure 6a). The singlet CS state observed at 5.8 ps diminished at $60 \mathrm{ps}$, and the decay profile at $634 \mathrm{~nm}$ was analyzed with a single exponential to give the rate constant of 5.1 $\times 10^{10} \mathrm{~s}^{-1}$. Since the ${ }^{3}[\mathrm{PdPor}]^{*}-\mathrm{Fl}$ state was lower in energy than the CS state and the driving force to form the triplet excited state from the CS state was estimated to be $0.1 \mathrm{eV}$ (vide supra), the $\mathrm{CR}$ process from the CS state to ${ }^{3}[\mathrm{PdPor}]^{\star}$-FI may be relatively slow. Thus, the decay of the CS state should proceed with CR to the ground state rather than to ${ }^{3}[\mathrm{PdPor}]^{*}-\mathrm{Fl}$. The direct intersystem crossing from ${ }^{1}[\mathrm{PdP} o r]^{\star}-\mathrm{Fl}$ to ${ }^{3}[\mathrm{PdPor}]^{\star}-\mathrm{Fl}$ with a rate constant of ca. $10^{11} \mathrm{~s}^{-1}$ (Figure S16b in SI) may compete with the $\mathrm{CS}$ and $\mathrm{CR}$ processes. The ns-transient absorption spectrum of 2-Pd excited at $526 \mathrm{~nm}$ exhibited only absorption bands derived from the ${ }^{3}[\mathrm{PdPor}]^{*}-\mathrm{Fl}$ species, accompanying the bleaching of the Q-bands of the PdPor moiety (Figure 7a). The analysis of the time profile of the absorbance at $450 \mathrm{~nm}$ with single exponential afforded the decay rate constant of ${ }^{3}[\mathrm{PdPor}]^{*}$-Fl as $1.1 \times 10^{4} \mathrm{~s}^{-1}$ (Figure $7 b$ ). The decay rate constant is well matched with that for 3-Pd (Figure S18 in SI).

Photodynamics of Intramolecular Photoinduced Electron Transfer in the Presence of $\mathrm{Sc}^{3+}$. In the presence of 2 eq $(20$ $\mu \mathrm{M})$ of $\mathrm{Sc}(\mathrm{OTf})_{3}, \mathbf{2}-\mathbf{P d}(10 \mu \mathrm{M})$ forms a 1:1 complex, 2-Pd $\cdots \mathrm{Sc}^{3+}$ in $\mathrm{PhCN}$ as a major species judging from the binding constant $\left(K_{1}\right.$ $=2.2 \times 10^{5} \mathrm{M}^{-1}$ ) determined by the spectral titration in Figure 2 (vide supra). The fs laser flash photolysis of $2-\mathbf{P d} \cdots \mathrm{Sc}^{3+}$ in the presence of 2 eq of $\mathrm{Sc}(\mathrm{OTf})_{3}$ in deaerated $\mathrm{PhCN}$ exhibited an enhanced absorption band at $634 \mathrm{~nm}$ assigned to the PdPor ${ }^{++}$
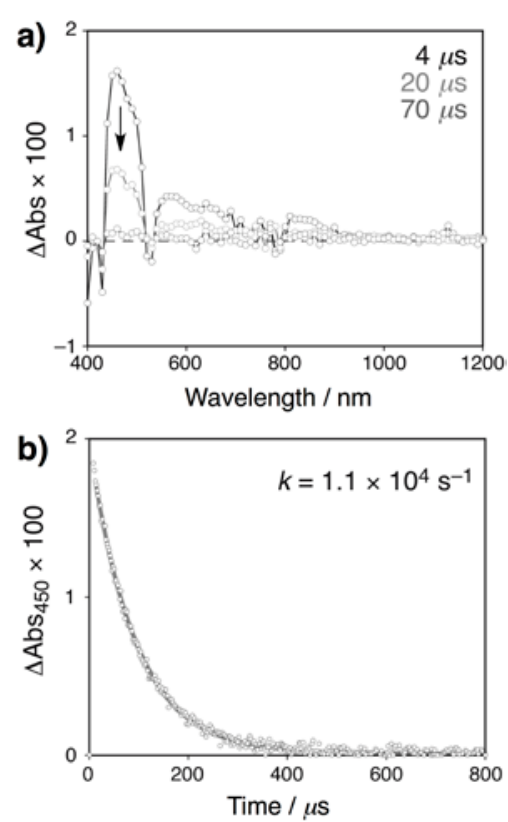

Figure 7. a) Nanosecond transient absorption spectra of 2-Pd $(25 \mu \mathrm{M})$ excited at $526 \mathrm{~nm}$ in deaerated $\mathrm{PhCN}$ taken at 4,20 , and $70 \mu \mathrm{s}$. b) The absorption time profile at $450 \mathrm{~nm}$.
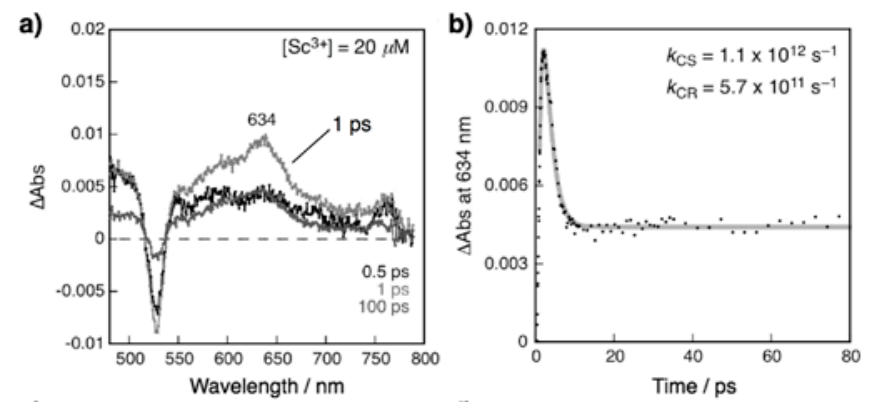

c)
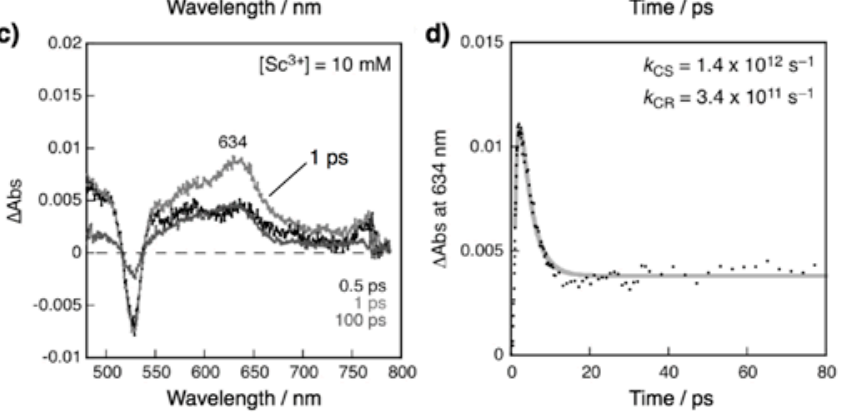

Figure 8. Femtosecond transient absorption spectra of 2-Pd $(10 \mu \mathrm{M})$ in the presence of $\mathrm{Sc}^{3+}$ ion [a) $20 \mu \mathrm{M}$, c) $10 \mathrm{mM}$ ] obtained by excitation at $430 \mathrm{~nm}$ in deaerated $\mathrm{PhCN}$ taken at $0.5 \mathrm{ps}, 1 \mathrm{ps}$, and $100 \mathrm{ps}$. Time profiles of the absorbance at $634 \mathrm{~nm}$ in the presence of $\mathrm{Sc}^{3+}$ ion [b] $\left.20 \mu \mathrm{M}, \mathrm{d}\right] 10 \mathrm{mM}$ ].

moiety (Figure 8a). The $\mathrm{CS}$ and $\mathrm{CR}$ rate constants were estimated to be $9.9 \times 10^{11}$ and $4.1 \times 10^{11} \mathrm{~s}^{-1}$, respectively, by time-profile analysis using bi-exponential curve-fitting of the absorbance change at $634 \mathrm{~nm}$ (Figure 8b). In the presence of large excess $\mathrm{Sc}^{3+}(10 \mathrm{mM})$, similar transient absorption spectra were observed as shown in Figure $8 \mathrm{c}$ and the $\mathrm{CS}$ rate constant $\left(1.4 \times 10^{12} \mathrm{~s}^{-1}\right)$ is larger than that in the presence of $20 \mu \mathrm{M} \mathrm{Sc}{ }^{3+}$ $\left(1.1 \times 10^{12} \mathrm{~s}^{-1}\right)$, whereas the CR rate constant $\left(3.4 \times 10^{11} \mathrm{~s}^{-1}\right)$ is smaller than that in the presence of $20 \mu \mathrm{M} \mathrm{Sc}^{3+}\left(5.7 \times 10^{11} \mathrm{~s}^{-1}\right)$ as shown in Figure $8 \mathrm{~d}$. The acceleration of the CS process as compared with that in the absence of $\mathrm{Sc}^{3+}\left(2.1 \times 10^{11} \mathrm{~s}^{-1}\right)$ is 
caused by the stabilization of the $1 \mathrm{e}^{-}$-reduced state of the $\mathrm{FI}$ moiety by the binding of $\mathrm{Sc}^{3+}$ ion, which results in increase of the driving force of electron transfer $\left(-\Delta G_{\mathrm{ET}}\right)$ to form the CS state from the ${ }^{1}[\mathrm{PdPor}]^{*}-\mathrm{Fl}$ state to be $1.18 \mathrm{eV}$, which is larger by +0.86 $\mathrm{eV}$ relative to that of $\mathrm{Sc}^{3+}$-free 2-Pd $\left(-\Delta \mathrm{G}_{\mathrm{ET}}=0.32 \mathrm{eV}\right)$. Similar acceleration of the CS process was also observed for 2-Pd complexes with $\mathrm{Y}^{3+}, \mathrm{Mg}^{2+}$ and $\mathrm{Zn}^{2+}$ (Table S1 and Figure S19 in $\mathrm{SI})$. The CR process of the CS state of $2-\mathbf{P d} \cdots \mathrm{Sc}^{3+}\left({ }^{1} \mathrm{CS}-\mathrm{Sc}\right)$ is also accelerated because of the much larger driving force of the $\mathrm{CR}$ process to the ground state $(0.95 \mathrm{eV})$ than that to the triplet excited state in the absence of $\mathrm{Sc}^{3+}(0.19 \mathrm{eV})$. It should be noted that the significant portion of the CS state in the presence of 20 $\mu \mathrm{M}$ and $10 \mathrm{mM} \mathrm{Sc}^{3+}$ remained after the initial fast decay as shown in Figure $8 \mathrm{~b}$ and $8 \mathrm{~d}$, respectively.

The existence of the long lived CS state was confirmed by nslaser flash photolysis as shown in Figure 9a, where the absorption bands at 450,630 and $820 \mathrm{~nm}$ due to the CS state remained at $800 \mu$ s (Figure 9a). The latter two bands at 630 and $820 \mathrm{~nm}$ were ascribed to the absorption of the $1 \mathrm{e}^{-}$-oxidized PdPor moiety on the basis of comparison with the spectrum of chemically oxidized 3-Pd, which exhibited the absorptions at 627 and $813 \mathrm{~nm}$ (Figure S16 in SI). The absorption band at $450 \mathrm{~nm}$ with bleaching at the shorter wavelength can be assigned to that of $1 \mathrm{e}^{-}$-reduced $\mathrm{Fl}$ moiety, since the $1 \mathrm{e}^{-}$-reduced species of $\mathrm{Sc}^{3+}$ bound $\mathrm{Dec}-\mathrm{Fl}$ with decamethyferrocene as the reducing reagent exhibits an absorption band at $480 \mathrm{~nm}$ (Figure S20 in SI). In the fs-transient absorption spectra, the CS state did not display the absorption of the $1 \mathrm{e}^{-}$-reduced $\mathrm{FI}$ moiety, because the absorption band was overlapped with the strong absorption of the ${ }^{3}[\mathrm{PdPor}]^{*}$ $\mathrm{Fl}$ species which is absent at $0.4 \mathrm{~ms}$ after the excitation. The absorption bands observed in the ns-laser flash photolysis in Figure $9 \mathrm{a}$ agree with those observed in the fs-laser flash photolysis in Figure 8a. Thus, we conclude that the spectrum
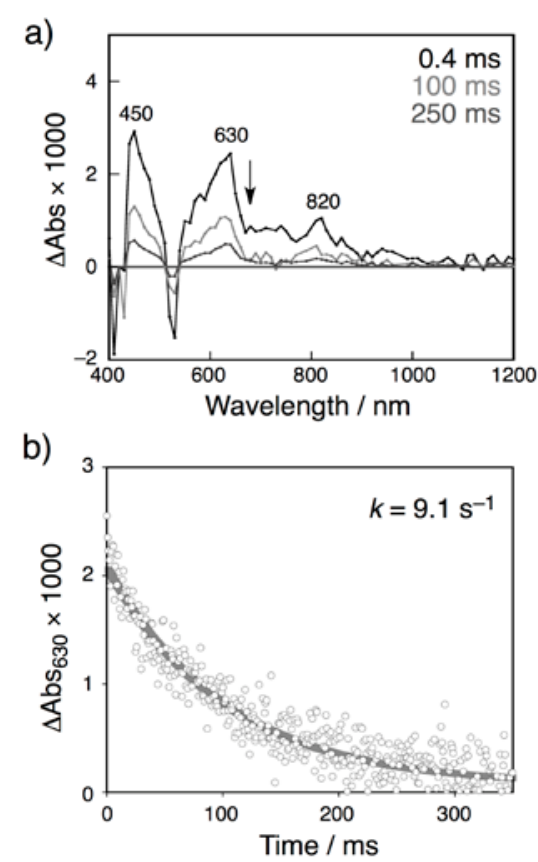

Figure 9. a) Nanosecond transient absorption spectra of 2-Pd $(25 \mu \mathrm{M})$ excited at $526 \mathrm{~nm}$ in $\mathrm{PhCN}$ in the presence of $\mathrm{Sc}(\mathrm{OTf})_{3}(50 \mu \mathrm{M})$ taken at $0.4,100$, and $250 \mathrm{~ms}$. b) The time profile of absorption at $630 \mathrm{~nm}$. observed in the ns-laser flash photolysis at $0.4 \mathrm{~ms}$ is ascribed due to a triplet CS state $\left({ }^{3} \mathrm{CS}\right)$ of 2-Pd $\cdots 2 \mathrm{Sc}^{3+}\left({ }^{3} \mathrm{CS}-2 \mathrm{Sc}\right.$; see the next section). Formation of such a long-lived ${ }^{3} \mathrm{CS}$ was not observed in the cases of the other metal ions $\left(\mathrm{Y}^{3+}, \mathrm{Mg}^{2+}, \mathrm{Zn}^{2+}\right)$. On the basis of the time profile of the absorption at $630 \mathrm{~nm}$ (Figure $9 \mathrm{~b}$ ), the lifetime of the ${ }^{3} \mathrm{CS}$ state was determined to be $110 \mathrm{~ms}\left(k_{\mathrm{CR}}=9.1 \mathrm{~s}^{-1}\right)$. To the best of our knowledge, this is the longest lifetime ever reported for CS states formed in dyads containing porphyrins at room temperature. ${ }^{[30,59]}$

The lifetime of the CS state is independent of the laser power of the excitation light, and thus, confirming that the decay of the triplet CS state occurs intramolecularly, not intermolecularly (Figure S21 in SI). The triplet CS state $\left({ }^{3}\left[\mathrm{PdPor}^{++}-\mathrm{Fl}^{--} \ldots \mathrm{Sc}^{3+}\right],{ }^{3} \mathrm{CS}-\right.$ Sc) may be formed through the triplet excited state $\left[{ }^{3}[\mathrm{PdPor}]^{*}-\right.$ $\mathrm{F}\left[\cdots \mathrm{Sc}^{3+}\right]$. The ${ }^{3} \mathrm{CS}-\mathrm{Sc}$ state may live long enough to react with another $\mathrm{Sc}^{3+}$ ion to form ${ }^{3}\left[\mathrm{PdPor}^{++}-\mathrm{Fl}^{\cdot-\ldots} \mathrm{SSc}^{3+}\right]\left({ }^{3} \mathrm{CS}-2 \mathrm{Sc}\right)$, which should exhibit the longer lifetime to be $110 \mathrm{~ms}$, via the intramolecular ET. This claim is supported by the fact that triplet CS states have been reported to show longer lifetimes than the corresponding singlet CS states. ${ }^{[60]}$

In order to confirm the triplet spin state of the long-lived CS species, we measured ESR spectrum of 2-Pd in the presence of 2 eq of $\mathrm{Sc}^{3+}$ in frozen $\mathrm{PhCN}$ at $4 \mathrm{~K}$ as shown in Figure 10. The sample was frozen with liq. He during the light illumination. A typical triplet ESR signal was observed at $g=4.03$, which was assigned to the signal due to a spin-forbidden transition $\left(\Delta m_{\mathrm{s}}=\right.$ \pm 2 ), as well as an intense signal due to the $\Delta m_{\mathrm{s}}= \pm 1$ transition at $g=1.998$, accompanying a fine structure derived from the zerofield splitting. The zero-field splitting parameter $D(G)$ was estimated to be $510 \mathrm{G}$, allowing us to determine the distance $(r$, $\AA$ ) between the two spin centers on the basis of Equation (8). ${ }^{[61]}$ The $r$ value was $3.8 \AA$, which was consistent with the distance between two radical centers bridged by a phenylene group as estimated on the basis of the crystal structure of 2-Pd (Figure $\mathrm{S} 22$ in $\mathrm{SI}) .{ }^{[62]}$

$$
r=\sqrt[3]{\frac{27,800}{D}}
$$

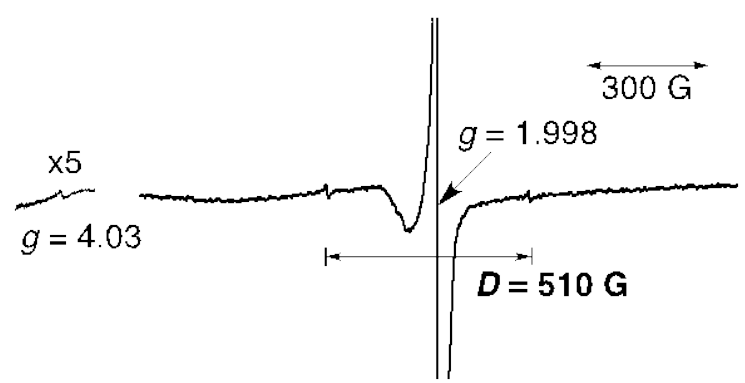

Figure 10. An ESR spectrum of 2-Pd $(0.5 \mathrm{mM})$ in the presence of $2 \mathrm{eq}$ of $\mathrm{Sc}^{3+}$ in frozen $\mathrm{PhCN}$ at $4 \mathrm{~K}$ during photoirradiation $(\lambda>340 \mathrm{~nm})$.

Mechanism to Elongate the Lifetime of the CS state in $\mathrm{Sc}^{3+}$ bound 2-Pd to Sub-second Region. Analysis on the rate constants of intramolecular photoinduced electron transfer and back electron transfer was made using a non-adiabatic Marcus equation (Equation (9)), where $V$ is the electronic coupling matrix 


$$
k_{\mathrm{ET}}=\left(\frac{4 \pi^{3}}{h^{2} \lambda k_{B} T}\right)^{1 / 2} V^{2} \exp \left[-\frac{\left(\Delta G_{\mathrm{ET}}+\lambda\right)^{2}}{4 \lambda k_{B} T}\right]
$$

element, $h$ is the Planck constant, $T$ is the absolute temperature, $\Delta G_{\mathrm{ET}}$ is the free energy change of electron transfer and $\lambda$ represents the reorganization energy of electron transfer. Drivingforce dependence of the rate constants obtained for the dyads was analyzed by using Equation (9) to obtain a Marcus plot as depicted in Figure 11. ${ }^{[62]}$ The $\lambda$ value for the Por-Fl dyads was

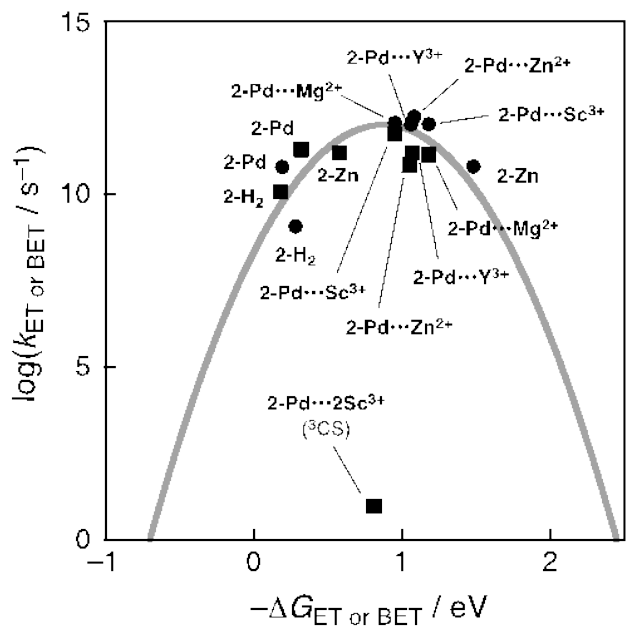

Figure 11. Driving force dependence of log $k_{\mathrm{ET}}$ and $\log k_{\mathrm{BET}}$ (Marcus plot) at $298 \mathrm{~K}$. filled circles: CS, filled squares: CR. The fitting curve was provided using Equation (9).

determined to be $0.90 \mathrm{eV}$ and the $V$ value to be $75 \mathrm{~cm}^{-1}{ }^{[64,65]}$ The zinc insertion into the porphyrin caused an increase in the driving force for the charge separation $\left(-\Delta G_{E T}=0.18 \mathrm{eV}\right.$ for $2-\mathrm{H}_{2}$ to $\Delta G_{\mathrm{ET}}=0.58 \mathrm{eV}$ for 1-Zn: See Table S1 in SI). The energy of the CS state of $2-\mathrm{H}_{2}$ is higher than that of the triplet excited state of the porphyrin when the charge recombination afforded the triplet excited state $\left(-\Delta G_{E T}=0.28 \mathrm{eV}\right.$ for $\left.\mathbf{2}-\mathrm{H}_{2}\right)$ as shown in Figure $12 \mathrm{a}$, whereas the energy of the CS state of $\mathbf{2 - Z n}$ is lower than that of the triplet excited state when the charge recombination occurs to produce the ground state $\left(-\Delta G_{E T}=1.48 \mathrm{eV}\right.$ for $\left.2-Z n\right)$ as shown in Figure 12b.

The energy of the CS state of 2-Pd is also higher than that of the triplet excited state of the porphyrin when the charge recombination afforded the triplet excited state $\left(-\Delta G_{\mathrm{ET}}=0.19 \mathrm{eV}\right.$ for 2-Pd) as shown in Figure 12c. However, binding of a metal ion such as $\mathrm{Sc}^{3+}$ ion to the $\mathrm{FI}$ moiety of 2-Pd stabilized the CS state due to the strong interaction between the metal ion and the reduced state of the $\mathrm{FI}$ moiety. As a result the energy of the CS state of 2-Pd $\cdots \mathrm{M}^{\mathrm{n}+}$ becomes lower than that of the triplet excited state of the porphyrin as shown in Figure 12d. The singlet CS state of $2-\mathbf{P d} \cdots \mathrm{Sc}^{3+}\left({ }^{1} \mathrm{CS}-\mathrm{Sc}\right)$ produced via the singlet excited state of the porphyrin exhibited short lifetime $(\tau=2.4 \mathrm{ps})$, because the driving force of the CR process $\left(-\Delta G_{\mathrm{ET}}=0.95 \mathrm{eV}\right)$ is at the top region of the Marcus parabola (Figure 11). In contrast, the triplet CS state of 2-Pd $\cdots \mathrm{Sc}^{3+}\left({ }^{3} \mathrm{CS}-\mathrm{Sc}\right)$ formed via the triplet excited state of the porphyrin exhibited a remarkably long lifetime (vide supra) and the rate constant was much smaller than the fitting curve in the Marcus plot in Figure 11. The intersystem crossing from the singlet excited state to the triplet excited state followed by rapid electron transfer to produce ${ }^{3} \mathrm{CS}-\mathrm{Sc}$ may compete with the formation of ${ }^{1} \mathrm{CS}-\mathrm{Sc}$ (Figure 12d). ${ }^{[66]}$

It is well known that triplet CS states exhibit long lifetimes, whose elongation ratios exceed over $2.5 \times 10^{5}$ times relative to the corresponding singlet CS state. ${ }^{[67]}$ Judging from the binding constants estimated by the UV-vis titration experiments (vide supra), the $\mathrm{Fl}$ moiety of 2-Pd holds one $\mathrm{Sc}^{3+}$ ion at the ground state under the conditions employed. The singlet CS state of 2Pd $\cdots \mathrm{Sc}^{3+}\left({ }^{1} \mathrm{CS}-\mathrm{Sc}\right)$ formed from the singlet excited state $\left({ }^{1}[\mathrm{PdPor}]^{\star}-\mathrm{F} \mid \cdots \mathrm{Sc}^{3+}\right)$ quickly decays to the ground state before the $\mathrm{Fl}^{-}$moiety takes one more $\mathrm{Sc}^{3+}$ ion. In contrast, the triplet $\mathrm{CS}$ a)

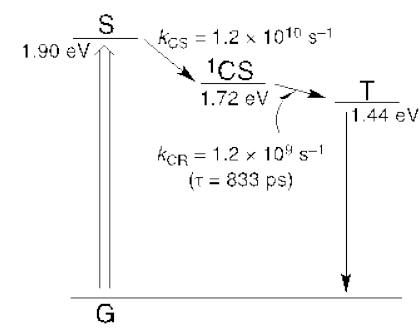

c)

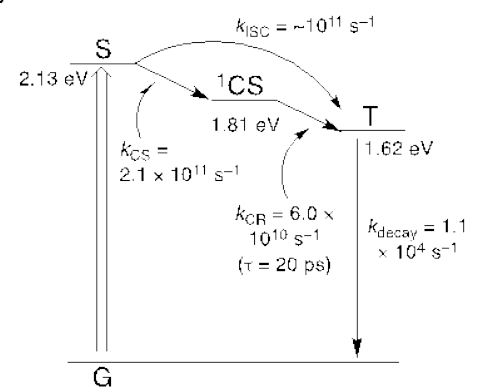

b)

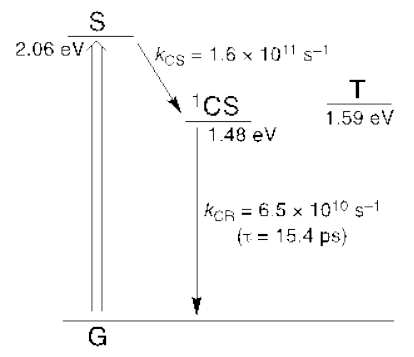

d)

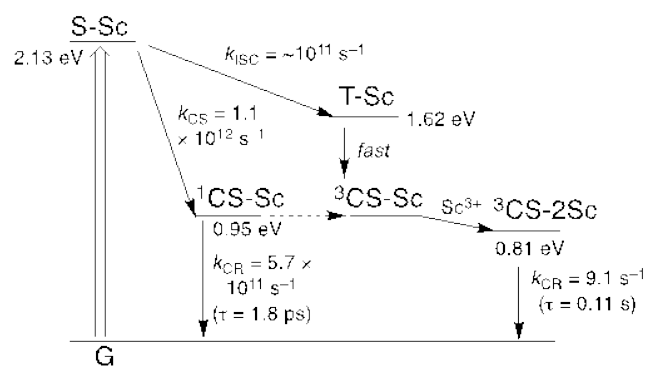

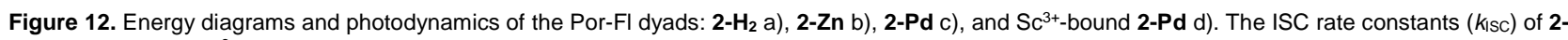
$\mathbf{P d}(\mathrm{c})$ and $\mathbf{2}-\mathbf{P d} \cdot \cdots \mathrm{Sc}^{3+} \mathrm{d}$ ) were estimated from that of 3-Pd in Figure S16b (SI). 
state of 2-Pd $\cdots \mathrm{Sc}^{3+}\left({ }^{3} \mathrm{CS}-\mathrm{Sc}\right)$ formed from the triplet excited state $\left({ }^{3}[\mathrm{PdPor}]^{*}-\mathrm{F} \mid \cdots \mathrm{Sc}^{3+}\right)$ has a lifetime long enough to bind the second $\mathrm{Sc}^{3+}$ ion at the $\mathrm{Fl}^{\cdot-}$ moiety, forming ${ }^{3}\left[\mathrm{PdPor}^{\circ+}-\mathrm{Fl}^{-}-\ldots 2 \mathrm{Sc}^{3+}\right]$ $\left({ }^{3} \mathrm{CS}-2 \mathrm{Sc}\right)$ as shown in Figure $12 \mathrm{~d} \cdot{ }^{[68]}$ In the case of other metal ions $\left(\mathrm{Y}^{3+}, \mathrm{Mg}^{2+}\right.$ and $\left.\mathrm{Zn}^{2+}\right)$, no binding of the second metal ion occurred to produce the long-lived CS state (vide infra). The long lifetime of ${ }^{3} \mathrm{CS}-2 \mathrm{Sc}$ results from the spin-forbidden CR to produce the singlet ground state. The intersystem crossing to the singlet CS state $\left({ }^{1} \mathrm{CS}-2 \mathrm{Sc}\right)$ may be prohibited due to the relatively large S-T gap of the dyad with short linkage.

Although intramolecular charge recombination in ${ }^{3} \mathrm{CS}-2 \mathrm{Sc}$ is spin-forbidden, intermolecular charge recombination between two ${ }^{3} \mathrm{CS}-2 \mathrm{Sc}$ molecules is spin-allowed. Such an intermolecular charge recombination may be retarded by a large reorganization energy of electron transfer of the flavin moiety binding two $\mathrm{Sc}^{3+}$ ions. To confirm this hypothesis, we determined the reorganization energy $(\lambda)$ of DecFI binding two $\mathrm{Sc}^{3+}$ ions. The rates of electron-transfer reduction of DecFI by three kinds of ferrocene derivatives [ferrocene: $\mathrm{Fc}\left(E_{\mathrm{ox}}=+0.37 \mathrm{~V}\right.$ vs. SCE $), 1,1$ dimethylferrocene: $\mathrm{Me}_{2} \mathrm{Fc}\left(E_{\mathrm{ox}}=+0.26 \vee v s\right.$. SCE $)$ and 1,2,3,4,5pentamethylferrocene: $\mathrm{Me}_{5} \mathrm{Fc}\left(E_{\mathrm{ox}}=+0.10 \mathrm{~V}\right.$ vs. SCE)] were determined by monitoring the rise of the absorbance due to DecFl ${ }^{-}-\ldots 2 \mathrm{Sc}^{3+}$ at $480 \mathrm{~nm}$ in PhCN at $298 \mathrm{~K}$.

The rate constants were analyzed using Equation (10), ${ }^{[24]}$ where $k_{\text {diff }}$ and $k_{\text {-diff }}$ are the diffusion and dissociation rate constants in the encounter complex and parameter $Z$ is defined with Equation (11). The rate constants were plotted against the

$$
\begin{aligned}
& \frac{1}{k_{\text {et }}}=\frac{1}{k_{\text {diff }}}+\frac{1}{Z \exp \left[-(\lambda / 4)\left(1+\Delta G_{\mathrm{et}} / \lambda\right)^{2} / k_{\mathrm{B}} T\right]} \\
& Z=\frac{k_{\mathrm{B}} T}{h} \times \frac{k_{\text {diff }}}{k_{- \text {diff }}}
\end{aligned}
$$

driving forces $\left(-\Delta G_{\mathrm{ET}}\right)$ of $\mathrm{ET}$ from ferrocences to DecFl (Figure S26 in SI). By fitting the plot using Equations (10) and (11), the reorganization energy $(\lambda)$ was estimated to be $1.95 \mathrm{eV}$. Thus, the reorganization energy of electron transfer of two- $\mathrm{Sc}^{3+}$-bound flavin is much larger than that of $\mathrm{Fl}$ without $\mathrm{Sc}^{3+}(0.68 \mathrm{eV}){ }^{[24]}$ On the basis of the Marcus plot in Figure S26 (SI), we could estimate the rate constant for a putative intermolecular $\mathrm{CR}$ process to be 1 $\times 10^{8} \mathrm{M}^{-1} \mathrm{~s}^{-1}$ at $-\Delta G_{\mathrm{ET}}=0.81 \mathrm{eV}$. The first-order rate constant of the intermolecular process at a concentration of the CS state $\left(\sim 10^{-7} \mathrm{M}\right)$, which corresponds to the initial concentration in Figure $9 b,{ }^{[69]}$ is estimated to be $\sim 10 \mathrm{~s}^{-1}$. This rate constant is comparable to that determined from Figure $9 \mathrm{~b}\left(9.1 \mathrm{~s}^{-1}\right)$. However, the intermolecular $\mathrm{CR}$ of two triplet $(S=1)$ molecules afford spin states of $S=2,1$ and 0 with the ration of 5:3:1. Thus, only $1 / 9$ leads to the singlet ground state. In such a case, the intermolecular CR (second-order) process should be, if any, negligible, in comparison with the intramolecular CR (first-order) process. This is consistent with the independency of the lifetime from the laser power of excitation as mentioned above (see Figure S21 in SI).

\section{Conclusion}

We have synthesized a porphyrin-flavin linked dyad and its zinc and palladium complexes with clear localization of the HOMO on the porphyrin moiety and the LUMO on the flavin moiety as demonstrated by DFT calculations. Spectroscopic and electrochemical studies revealed that the energy levels of the CS states and the triplet excited states of Por-Fl dyads can be controlled by a metal center of the porphyrin moiety. Especially, the $\mathrm{Pd}^{\text {"l }}$ insertion to the porphyrin moiety results in not only lowering the energy level of the CS state but also the enhancement of ISC to afford the triplet excited state. In addition, $\mathrm{Sc}^{3+}$ ion that is a strong Lewis acid binds to the $\mathrm{Fl}$ moiety of the dyads in a stepwise manner to afford a large anodic shift of the reduction potential of the FI moiety to stabilize the CS state and a larger reorganization energy of ET to retard the ET reaction. In the case of the palladium(II) complex of the dyad (2-Pd), the $\mathrm{Sc}^{3+}$ binding to the $\mathrm{FI}$ moiety allowed us to observe two kinds of CS states formed by photoinduced electron transfer from the PdPor moiety to the $\mathrm{Fl}$ part: one is the singlet CS state, which is mainly formed from the singlet excited state of $2-\mathbf{P d} \cdots \mathrm{Sc}^{3+}$ and quickly decays to the ground state, and the other is the triplet CS state, which exhibits the longest lifetime $(\tau=0.11 \mathrm{~s})$ for CS states in dyads having porphyrin moieties reported so far. This remarkable elongation of the lifetime for the CS state results from the triplet spin state of the CS state and the second $\mathrm{Sc}^{3+}$-binding to form ${ }^{3}\left[\mathrm{PdPor}^{++}-\mathrm{Fl}^{-}-\ldots 2 \mathrm{Sc}^{3+}\right]\left({ }^{3} \mathrm{CS}-2 \mathrm{Sc}\right)$ to enlarge the reorganization energy of intermolecular charge recombination. Thus, the control of the spin state of an electron donor-acceptor dyad by sitespecific binding of appropriate metal ions may be a versatile strategy to gain an extremely long-lived CS state.

\section{Acknowledgements}

This work was partially supported by Grants-in-Aid (No. 20108010, 23111703 23750014, 24245011, 26620154, 26288037) from Japan Promotion of Science and Technology (JSPS) and an Advanced Low Carbon Technology Research and Development (ALCA) program from Japan Science Technology Agency (JST to S.F.), Japan. T. K. also appreciates financial supports from The Iwatani Naoji Foundation and Mitsubishi Foundation.

Keywords: photoinduced electron transfer • charge separation • metalloporhyrins $\bullet$ metal ion binding

[1] a) Photoinduced Electron Transfer (Eds.: M. A. Fox, M. Chanon), Elsevier Amsterdam, 1988, Part A-D; b) Oxygenic Photosynthesis: The Light Reactions (Eds.: D. R. Ort, C. F. Yocum), Kluwer Academic Publishers, Dordrecht, 1996; c) Fundamentals of Photoinduced Electron Transfer (Ed.: G. J. Kavarnos), Wiley-VCH, New York, 1993; d) Electron Transfer in Chemistry (Ed.: Balzani), Wiley-VCH, Weinheim, 2001, Vols. 1-5.

[2] a) T. M. Clarke, J. R. Durrant, Chem. Rev. 2010, 110, 6736; b) M. G. Walter, E. L. Warren, J. R. McKone, S. W. Boettecher, Q. Mi, E. A. Santori, N. S. Lewis, Chem. Rev. 2010, 110, 6446

[3] a) A. J. Esswein, D. G. Nocera, Chem. Rev. 2007, 107, 4022; b) A. Maldotti, A. Molinari, R. Amadelli, R. Chem. Rev. 2002, 102, 3811; c) M. Fagnoni, D. Dondi, D. Ravelli, A. Albini, A. Chem. Rev. 2007, 107, 2725; d) S. Fukuzumi, Bull. Chem. Soc. Jpn. 2006, 79, 177.

[4] a) The Photosynthetic Reaction Center (Eds.: J. Deisenhofer, J. R. Norris), Academic Press, San Diego, 1993; b) An Oxygenic Photosynthetic Bacteria (Eds.: R. E. Blankenship, M. T. Madigan, C. E. Bauer), Kluwer Academic, Dordrecht, 1995; c) A. J. Hoff, J. Deisenhofer, Phys. Rep. 1997, 287, 1; d) J. Deisenhofer, H. Michel, Angew. Chem. 1989, 101, 872; Angew. Chem., Int. Ed. Engl. 1989, 28, 829; e) P. Heathcote, P. K. Fyfe, M. R. Jones, Trends Biochem. Sci. 2002, 27, 79; f) 
Handbook of Photosynthesis, 2nd ed. (Ed.: M. Pessarakli), CRC, Boca Raton, 2005; g) Photosynthetic Light Harvesting (Eds.: R. Cogdell, C. Mullineaux), Sprigner, Dordrecht, 2008; h) J. Barber, Q. Rev. Biophys. 2003, 36, 71; i) Primary Processes of Photosynthesis (Ed.: Renger), Royal Society of Chemistry, Cambridge, 2008, Part 1, 2.

[5] a) J. Barber, Inorg. Chem. 2008, 47, 1700; b) A. Zouni, H. T. Witt, J. Kern P. Fromme, N. Krauss, W. Saenger, P. Orth, Nature 2001, 409, 739; c) N Kamiya, J. R. Shen, Proc. Natl. Acad. Sci. U.S.A. 2003, 100, 98; d) K. N. Ferreira, T. M. Iverson, K. Maghlaoui, J. Barber, S. Iwata, Science 2004 303, 1831; e) B. Loll, J. Kern, W. Saenger, A. Zouni, J. Biesiadka, Nature 2005, 438, 1040; f) Y. Umena, K. Kawakami, J.-R. Shen, N. Kamiya, Nature 2011, 473, 55.

[6] L. M. Utschig, M. C. Thurnauer, Acc. Chem. Res. 2004, 37, 439.

[7] a) C. Foote, Science 1968, 162, 963; b) G. Renger, C. Wolff, Biochim Biophys. Acta 1977, 460, 47; c) F. Boucher, M. van der Rest, G. Gingras Biochim. Biophys. Acta 1977, 461, 3349; d) A. Telfer, S. Dhami, S. M. Bishop, D. Phillips, J. Barber, Biochemistry 1994, 33, 14469

[8] a) M. R. Wasielewski, Chem. Rev. 1992, 92, 435; b) M. R. Wasielewski, Acc. Chem. Res. 2009, 42, 1910.

[9] a) D. Gust, T. A. Moore, A. L. Moore, S.-J. Lee, E. Bittersmann, D. K Luttrull, A. A. Rehms, J. M. Degraziano, X. C. Ma, F. Gao, R. E. Belford T. T. Trier, Science 1990, 240, 199; b) D. Gust, T. A. Moore, A. L. Moore Acc. Chem. Res. 1993, 26, 198; c) D. Gust, T. A. Moore, A. L. Moore Acc. Chem. Res. 2001, 34, 40; d) D. Gust, T. A. Moore, A. L. Moore, Acc. Chem. Res. 2009, 42, 1890; e) Y. Terazono, G. Kodis, P. A. Liddell, V. Garg, T. A. Moore, A. L. Moore, D. Gust, J. Phys. Chem. B 2009, 113, 7147.

[10] a) H. Imahori, K. Tamaki, D. M. Guldi, C. Luo, M. Fujitsuka, O. Ito, Y Sakata, S. Fukuzumi, J. Am. Chem. Soc. 2001, 123, 2607; b) H. Imahori, D. M. Guldi, K. Tamaki, Y. Yoshida, C. Luo, Y. Sakata, S. Fukuzumi, J. Am. Chem. Soc. 2001, 123, 6617; c) D. M. Guldi, H. Imahori, K. Tamaki, Y. Kashiwagi, H. Yamada, Y. Sakata, S. Fukuzumi, J. Phys. Chem. A 2004, 108, 541; d) H. Imahori, Y. Sekiguchi, Y. Kashiwagi, T. Sato, Y Araki, O. Ito, H. Yamada, S. Fukuzumi, Chem.-Eur. J. 2004, 10, 3184.

[11] H. Imahori, J. Phys. Chem. B 2004, 108, 6130.

[12] a) F. Spänig, M. Ruppert, J. Dannhäuser, A. Hirsch, D. M. Guldi, J. Am. Chem. Soc. 2009, 131, 9378; b) J. D. Megiatto, Jr., D. I. Schuster, S. Abwandner, G. de Miguel, D. M. Guldi, J. Am. Chem. Soc. 2010, 132 3847.

[13] a) S. Fukuzumi, Org. Biomol. Chem. 2003, 1, 609; b) S. Fukuzumi, Phys. Chem. Chem. Phys. 2007, 9, 1487; c) S. Fukuzumi, T. Kojima, J. Mater. Chem. 2008, 18, 1427; d) S. Fukuzumi, T. Honda, K. Ohkubo, T. Kojima Dalton Trans. 2009, 3880; e) K. Ohkubo, S. Fukuzumi, J. Porphyrins Phthalocyanines 2008, 12, 993; f) S. Fukuzumi, K. Ohkubo, J. Mater Chem. 2012, 22, 4575; g) K. Ohkubo, S. Fukuzumi, Bull. Chem. Soc. Jpn. 2009, 82, 303; h) S. Fukuzumi, K. Ohkubo, T. Suenobu, Acc. Chem. Res. 2014, 47, 1455

[14] a) S. Fukuzumi, K. Ohkubo, H. Imahori, J. Shao, Z. Ou, G. Zheng, Y Chen, R. K. Pandey, M. Fujitsuka, O. Ito, K. M. Kadish, J. Am. Chem. Soc 2001, 123, 10676; b) K. Ohkubo, H. Imahori, J. Shao, Z. Ou, K. M. Kadish Y. Chen, R. K. Pandey, M. Fujitsuka, O. Ito, S. Fukuzumi, J. Phys. Chem. A 2002, 106, 10991; c) K. Ohkubo, J. Shao, Z. Ou, K. M. Kadish, G. Li, R. K. Pandey, M. Fujitsuka, O. Ito, H. Imahori, S. Fukuzumi, Angew. Chem., Int. Ed. 2004, 43, 853; d) S. Fukuzumi, K. Ohkubo, W. E, Z. Ou, J. Shao K. M. Kadish, J. A. Hutchison, K. P. Ghiggino, P. J. Sintic, M. J. Crossley, J. Am. Chem. Soc. 2003, 125, 14984; e) K. Ohkubo, R. Garcia, P. J. Sintic, T. Khoury, M. J. Crossley, K. M. Kadish, S. Fukuzumi, Chem.-Eur. J. 2009, 15, 10493.

[15] a) F. D'Souza, R. Chitta, S. Gadde, L. M. Rogers, P. A. Karr, M. E. Zandler, A. S. D. Sandanayaka, Y. Araki, O. Ito, Chem.-Eur. J. 2007, 13, 916; b) F. D'Souza, O. Ito, Chem. Commun. 2009, 4913; c) F. D'Souza, E. Maligaspe, K. Ohkubo, M. E. Zandler, N. K. Subbaiyan, S. Fukuzumi, J. Am. Chem. Soc. 2009, 131, 8787; d) F. D'Souza, N. K. Subbaiyan, Y. Xie, J. P. Hill, K. Ariga, K. Ohkubo, S. Fukuzumi, J. Am. Chem. Soc. 2009,
131, 16138; e) F. D'Souza, R. Chita, K. Ohkubo, M. Tasior, N. K. Subbaiyan, M. E. Zandler, M. Rogacki, D. T. Gryko, S. Fukuzumi, J. Am. Chem. Soc. 2008, 130, 14263.

[16] a) H. Nakagawa, K. Ogawa, A. Satake, Y. Kobuke, Chem. Commun. 2006, 1560; b) Y. Kuramochi, A. Satake, M. Itou, K. Ogawa, Y. Araki, O. Ito, Y. Kobuke, Chem.-Eur. J. 2008, 14, 2827.

[17] A. Nakano, A. Osuka, T. Yamazaki, Y. Nishimura, S. Akimoto, I. Yamazaki, A. Itaya, M. Murakami, H. Miyasaka, Chem.-Eur. J. 2001, 7, 3134.

[18] a) D. I. Schuster, K. Li, D. M. Guldi, A. Palkar, L. Echegoyen, C. Stanisky, R. J. Cross, M. Niemi, N. V. Tkachenko, H. Lemmetyinen, J. Am. Chem. Soc. 2007, 129, 15973; b) K. Kaunisto, V. Chukharev, N. V. Tkachenko, A. Efimov, H. Lemmetyinen, J. Phys. Chem. C 2009, 113, 3819; c) H. Lemmetyinen, N. V. Tkachenko, A. Efimov, M. Niemi, J. Phys. Chem. C 2009, 113, 11475.

[19] a) S. I. van Dijk, C. P. Groen, F. Hartl, A. M. Brouwer, J. W. Verhoeven, J. Am. Chem. Soc. 1996, 118, 8425; b) S. Takahashi, K. Nozaki, M. Kozaki, S. Suzuki, K. Keyaki, A. Ichimura, T. Matsushita, K. Okada, J. Phys. Chem. A 2008, 112, 2533; c) S. Suzuki, R. Sugimura, M. Kozaki, K. Keyaki, K. Nozaki, N. Ikeda, K. Akiyama, K. Okada, J. Am. Chem. Soc. 2009, 131, 10374; d) F. Nastasi, F. Puntoriero, S. Campagna, S. Diring, R. Ziessel, Phys. Chem. Chem. Phys. 2008, 10, 3982; e) T. Honda, T. Nakanishi, K. Ohkubo, T. Kojima, S. Fukuzumi, J. Phys. Chem. C 2010, 114, 14290.

[20] K. J. Smit, J. M. Warman, J. Luminescence 1988, 42, 149.

[21] M. Murakami, K. Ohkubo, T. Nanjo, K. Souma, N. Suzuki, S. Fukuzumi, S. ChemPhysChem 2010, 11, 2594.

[22] Porphyrin Handbook (Eds.; K. M. Kadish, K. M. Smith, R. Guilard), Academic Press, San Diego, 2000.

[23] V. V. Vasil'ev, I. A. Blinova, I. V. Golovina, S. M. Borisov, J. Appl. Spec 1999, 66, 583.

[24] M. Murakami, K. Ohkubo, S. Fukuzumi, Chem.-Eur. J. 2010, 16, 7820.

[25] a) C. T. Walsh, Acc. Chem. Res. 1980, 13, 148; b) C. T. Walsh, Acc. Chem. Res. 1986, 19, 216; c) T. C. Bruice, Acc. Chem. Res. 1980, 13, 256; d) P. F. Heelis, R. F. Hartman, S. D. Rose, Chem. Soc. Rev. 1995, 289; e) S. Fukuzumi, T. Tanaka, In Photoinduced Electron Transfer, Part C (Eds.: M. A. Fox, M. Chanon), Elsevier, Amsterdam, 1988, Part C, pp. 636; f) G. Tollin, In Electron Transfer in Chemistry (Ed.: V. Balzani), Wiley-VCH, Weinheim, 2001, Vol. 4, pp. 202-231.

[26] a) J. Lauterwein, P. Hemmerich, J.-M. Lhoste, Inorg. Chem. 1975, 14, 2152; b) M. J. Clarke, Comm. Inorg. Chem. 1984, 3, 133; c) M. J. Clarke, Rev. Inorg. Chem. 1980, 2, 27; d) W. Kaim, B. Schwederski, O. Heilmann F. M. Hornung, Coord. Chem. Rev. 1999, 182, 323; e) S. Fukuzumi, T. Kojima, J. Biol. Inorg. Chem. 2008, 13, 321.

[27] a) S. Fukuzumi, K. Ohkubo, Coord. Chem. Rev. 2010, 254, 372; b) S. Fukuzumi, S. Kuroda, T. Tanaka, Chem. Lett. 1984, 417; c) S. Fukuzumi, S. Kuroda, T. Tanaka, J. Am. Chem. Soc. 1985, 107, 3020.

[28] M. B. Twitchett, J. C. Ferrer, P. Siddarth, A. G. Mauk, J. Am. Chem. Soc. 1997, 119, 435.

[29] a) R. Nayar, A. M. Brun, A. Harriman, T. P. Begley J. Chem. Soc., Chem. Commun. 1992, 395; b) A. Gouloumis, G. M. A. Rahman, J. Abel, G. de la Torre, P. Vázquez, L. Echogoyen, D. M. Guldi, T. Torres, Aust. J. Chem. 2008, 61, 256.

[30] a) S. Fukuzumi, H. Mori, H. Imahori, T. Suenobu, Y. Araki, O. Ito, K. M. Kadish, J. Am. Chem. Soc. 2001, 123, 12458; b) K. Okamoto, S. Fukuzumi, J. Am. Chem. Soc. 2004, 126, 13922; c) K. Okamoto, Y. Mori, H. Yamada, H. Imahori, S. Fukuzumi, Chem.-Eur. J. 2004, 10, 474; d) S. Fukuzumi, K. Ohkubo, J. Ortiz, A. M. Gutiérrez, F. Fernández-Lázaro, Á. Sastre-Santos, Chem. Commun. 2005, 3814; e) K. Ohkubo,J. Ortiz, L. Martín-Gomis, F. Fernández-Lázaro, Á. Sastre-Santos, S. Fukuzumi, Chem. Commun. 2007, 589.

[31] T. K. Miyamoto, N. Sugita, Y. Matsumoto, Y. Sasaki, M. Konno, Chem. Lett. 1983, 1695. 
[32] M. J. Crossley, L. G. King, I. A. Newsom, C. S. Sheehan, J. Chem. Soc., Perkin Trans. 1 1996, 2675.

[33] M. J. Plater, S. Aiken, G. Bourhill, Tetrahedron 2002, 58, 2405.

[34] a) C.-H. Lee, J. S. Lindsey, Tetrahedron 1994, 50, 11427; b) R. Beavington, P. L. Burn, J. Chem. Soc., Perkin Trans. 1 1999, 5, 583.

[35] a) M. Murakami, K. Ohkubo, T. Hasobe, V. Sgobba, D. M. Guldi, F. Wessendorf, A. Hirsch, S. Fukuzumi, J. Mater. Chem. 2010, 20, 1457; b) W. B. Cowden, P. K. Halladay, R. B. Cunningham, N. H. Hunt, I. A. Clark J. Med. Chem. 1991, 34, 1818.

[36] a) H. E. Gottlieb, V. Kotlyar, A. Nudelman, J. Org. Chem. 1997, 62, 7512 b) G. R. Fulmer, A. J. M. Miller, N. H. Sherden, H. E. Gottlieb, A Nudelman, B. M. Stoltz, J. E. Bercaw, K. I. Goldberg, Organometallics 2010, 29, 2176.

[37] a) K. Wakita, Yadokari-XG, Software for Crystal Structure Analyses 2001; b) C. Kabuto, S. Akine, T. Nemoto, E. Kwon, Release of Software (Yadokari-XG 2009) for Crystal Structure Analyses. J. Cryst. Soc. Jpn. 2009, 51, 218.

[38] P. V. P. Sluis, A. L. Spek, Acta Crystallogr. 1990, A46, 194

[39] S. Fukuzumi, K. Yasui, T. Suenobu, K. Ohkubo, M. Fujitsuka, O. Ito, J. Phys. Chem. 2001, 105, 10501.

[40] T. Honda, T. Kojima, S. Fukuzumi, Chem. Commun. 2009, 4994.

[41] M. J. Frisch, et al. Gaussian 03; Gaussian, Inc.: Wallingford, CT, 2004 The full list of authors is given in $\mathrm{SI}$.

[42] A. D. Becke, J. Chem. Phys. 1993, 98, 5648.

[43] a) W. J. Hehre, R. Ditchfield, J. A. Pople, J. Chem. Phys. 1972, 56, 2257 b) V. A. Rassolov, J. A. Pople, M. A. Ratner, T. L. Windus, J. Chem. Phys. 1998, 109, 1223

[44] a) J. Hay, W. R. Dadt, J. Chem. Phys. 1985, 82, 270; b) J. Hay, W. R. Dadt, J. Chem. Phys. 1985, 82, 284; c) J. Hay, W. R. Dadt, J. Chem. Phys. 1985, 82, 299.

[45] R. Dennington, II, T. Keith, J. Millam, K. Eppinnett, W. L. Hovell, R Gilliland, GaussView, Semichem, Inc., Shawnee Mission, KS, 2003.

[46] M. J. Blanco, J. C. Chambron, V. Heitz, J. P. Sauvage, Org. Lett. 2000, 2, 3051.

[47] D. I. Schuster, S. MacMahon, D. M. Guldi, L. Echegoyen, S. E. Braslavsky, Tetrahedron 2006, 62, 1928.

[48] a) N. Choy, K. C. Russell, J. C. Alvarez, A. Fider, Tetrahedron Lett. 2000 41, 1515; b) P. Chattopadhyay, R, Rai, P. S. Pandey, Synth. Commun. 2006, 36, 1857.

[49] The reaction of $\mathbf{2}-\mathbf{H}_{2}$ of $\mathrm{Pd}(\mathrm{OAc})_{2}$ resulted in the complexation of the $\mathrm{Pd}^{\prime \prime}$ ion with the flavins moiety as well as its insertion to the porphyrin part (Anal: Calcd for $\mathrm{C}_{78} \mathrm{H}_{80} \mathrm{~N}_{8} \mathrm{O}_{2} \mathrm{Pd} \cdot \mathrm{Pd}\left(\mathrm{OCOCH}_{3}\right)_{2} \cdot \mathrm{CHCl}_{3}: \mathrm{C} 61.85, \mathrm{H} 5.44, \mathrm{~N}$ 6.95; Found: C 62.17, H 5.65, N 6.84). Removal of the flavin-bound Pd" ion by treatment with trifluoroacetic acid or aqueous $\mathrm{HClO}_{4}(70 \%)$ was unsuccessful.

[50] L. Xu, Z. Li, W. Tan, T. He, F. Liu, D. Chen, Spectrochim. Acta, Part A 2005, 62, 850

[51] A. Harriman, J. Chem. Soc., Faraday Trans. 1981, 77, 1281.

[52] K. M. Kadish, W. E, P. J. Sintic, Z. Ou, J. Shao, K. Ohkubo, S. Fukuzumi L. J. Govenlock, J. A. McDonald, A. C. Try, Z.-L. Cai, J. R. Reimers, M. J. Crossley, J. Phys. Chem. B 2007, 111, 8762.

[53] S. Fukuzumi, Y. Morimoto, H. Kotani, P. Naumov, Y.-M. Lee, W. Nam Nat. Chem. 2010, 2, 756

[54] S. Fukuzumi, K. Ohkubo, J. Am. Chem. Soc. 2002, 124, 10270

[55] T. Honda, T. Kojima, S. Fukuzumi, Chem. Commun. 2009, 4994.

[56] S. Fukuzumi, Y. Kondo, S. Mochizuki, T. Tanaka, T. J. Chem. Soc. Perkin Trans. 2 1989, 1753.

[57] A. Harriman, J. Chem. Soc., Faraday 1 1980, 76, 1978.

[58] a) Z. Gasyna, W. R. Browett, M. J. Stillman, Inorg. Chem. 1985, 24, 2440; b) J. Springer, G. Kodis, L. de la Garza, A. L. Moore, T. A. Moore, D. Gust, D. J. Phys. Chem. A 2003, 107, 3567

[59] The longest lifetime of a CS state reported to date was $23 \pm 4 \mathrm{~ms}$ (ref. $30(e))$. Compared to this value, the lifetime of the CS state obtained here for 1-Pd was five-times longer.
[60] a) T. Miura, W. R. Wasielewski, J. Am. Chem. Soc. 2011, 133, 2844; b) R Carmieli, A. L. Smeigh, S. M. Mickley Conron, A. K. Thazhathveetil, M. Fuki, Y. Kobori, F. D. Lewis. M. R. Wasielewski, J. Am. Chem. Soc. 2012 134, 11251.

[61] T. Nakanishi, T. Kojima, K. Ohkubo, T. Hasobe, K. Nakayama, S. Fukuzumi, Chem. Mater. 2008, 20, 7492.

[62] On the basis of the crystal structure of 2-Pd (Figure 1), the distance between $\mathrm{N} 10$ of the $\mathrm{Fl}$ moiety and the ortho-carbons of the phenylene bridge at the Por side was estimated to be $3.7 \AA$ (Figure S22 in $\mathrm{SI}$ ). A radical cation of $\mathrm{Pd}^{\text {"l }}$ tetraphenylporphyrinate was indicated by the DFT calculation to have a large spin density on the ortho-carbons of the mesophenyl groups (Figure S23 in SI). See also: S. Fukuzumi, Y. Endo, H. Imahori, J. Am. Chem. Soc. 2002, 124, 10974.

[63] The driving forces of ET for 2-Pd in the presence of $\mathrm{Y}^{3+}, \mathrm{Mg}^{2+}$, and $\mathrm{Zn}^{2+}$ were estimated on the basis of the reduction potential $\left(E_{\text {red }}\right)$ of DecFl in the presence of the corresponding metal salts in $\mathrm{PhCN}$ : $E_{\text {red }}=-0.01 \mathrm{~V}$ vs SCE for $\mathrm{Y}^{3+},-0.12 \mathrm{~V}$ for $\mathrm{Mg}^{2+},+0.01 \mathrm{~V}$ for $\mathrm{Zn}^{2+}$ (Table S1 and Figure S24 in $\mathrm{SI}$ ). This estimation should be valid, because the $E_{\text {red }}$ of the FI moiety of 2-Pd and DecFl are not significantly different in the presence of 2 equiv of $\mathrm{Sc}(\mathrm{OTf})_{3}$ : $E_{\text {red }}=+0.11 \mathrm{~V}$ vs SCE for 2-Pd and $+0.17 \mathrm{~V}$ for DecFI.

[64] The difference in the central metals of the porphyrin moiety was reported to result in little effect on the reorganization energies for the CS and CR reactions, see: a) M. R. Wasielewski, M. D. Nicmczyk, W. A. Svec, E. B. Pewitt, J. Am. Chem. Soc. 1985, 107, 1080; b) G. L. Gaines, M. P. O'Neil, W. A. Svec, M. P. Niemczyk, M. R. Wasielewski, J. Am. Chem. Soc. 1991 $113,719$.

[65] The electronic coupling constant was estimated to be $71 \mathrm{~cm}^{-1}$, which is comparable to that for other porphyrin-acceptor dyads. See ref. 63 and a) H. Heitele, F. Pöllinger, T. Häberle, M. E. Michel-Beyerle, H. A. Staab, J. Phys. Chem. 1994, 98, 7402; b) N. Mataga, H. Chosrowjan, Y. Shibata, N. Yoshida, A. Osuka, T. Kikuzawa, T. Okada, J. Am. Chem. Soc. 2001, 123 12422; c) T. Honda, T. Nakanishi, K. Ohkubo, T. Kojima, S. Fukuzumi, J. Am. Chem. Soc. 2010, 132, 10155.

[66] The rate constant of intersystem crossing $\left(k_{\mid S C}\right)$ is estimated to be ca $10^{11} \mathrm{~s}^{-1}$ from that of the reference compound (3-Pd) in Figure S16b. Judging from the driving force dependence of log $k_{\mathrm{ET}}$ in Figure 11 the subsequent electron transfer to produce ${ }^{3} \mathrm{CS}-\mathrm{Sc}$ (ca. $10^{12} \mathrm{~s}^{-1}$ ) may be much faster than the intersystem crossing (Figure 12d). The intersystem crossing from ${ }^{1} \mathrm{CS}-\mathrm{Sc}$ to ${ }^{3} \mathrm{CS}$-Sc may be negligible at this time scale $(<10$ ps).

[67] a) B. Gei, C. Lambert, Chem. Commun. 2009, 1670; b) T. Honda, T. Nakanishi, K. Ohkubo, T. Kojima, S. Fukuzumi, J. Phys. Chem. C 2010, 114, 14290; c) S.-H. Lee, A. G. Larsen, K. Ohkubo, Z.-L. Cai, J. R. Reimers, S. Fukuzumi, M. J. Crossley, Chem. Sci. 2012, 3, 257; d) V. M. Blas-Ferrando, J. Ortiz, L. Bouissane, K. Ohkubo, S. Fukuzumi, F. Fernández-Lázaroa, Á. Sastre-Santos, Chem. Commun. 2012, 48, 6241; e) C. Kaiser, A. Schmiedel, M. Holzapfel, C. Lambert, J. Phys. Chem. C 2012, 116, 15265

[68] The transient absorption spectra of 2-Pd in $\mathrm{Sc}^{3+}$-saturated $\mathrm{PhCN}$, where two $\mathrm{Sc}^{3+}$ ions bind to the $\mathrm{Fl}$ moiety of 2-Pd at the ground state, gave a relatively short lifetime $(\tau=910 \mu \mathrm{s})$ of the ${ }^{3} \mathrm{CS}$ state (Figure $\mathrm{S} 25$ in $\mathrm{SI}$ ). This also suggests that the difference in the affinity to the $\mathrm{Sc}^{3+}$-ion between the neutral and $1 \mathrm{e}^{-}$-reduced states of the $\mathrm{Fl}$ moiety plays an important role to attain the remarkable long lifetime of the ${ }^{3} \mathrm{CS}$ state of 2 Pd through the increase in the reorganization energy $(\lambda)$ of the ET processes.

[69] The initial concentration of ${ }^{3} \mathrm{CS}-2 \mathrm{Sc}$ was determined from the absorbance at $630 \mathrm{~nm}$ due to ${ }^{3} \mathrm{CS}-2 \mathrm{Sc}(0.0022)$ at $1.6 \mathrm{~ms}$ and the extinction coefficient of ${ }^{3} \mathrm{CS}-2 \mathrm{Sc}$ at $630 \mathrm{~nm}$, which was deduced from that of PdPor $^{\circ+}$ (Figure S17 in SI) to be $2 \times 10^{4} \mathrm{M}^{-1} \mathrm{~cm}^{-1}$.

Received: ((will be filled in by the editorial staff))

Revised: ((will be filled in by the editorial staff)) Published online: ((will be filled in by the editorial staff)) 
Entry for the Table of Contents (Please choose one layout only)

Layout 1:

\section{FULL PAPER}

A porphyrin-flavin linked dyad and its zinc and palladium complexes were newly synthesized and the X-ray crystal structure of the $\mathrm{Pd}$ complex was determined. The $\mathrm{Pd}-\mathrm{Sc}^{3+}$ complex afforded a remarkably long lifetime of 110 $\mathrm{ms}$ of the charge-separated state.

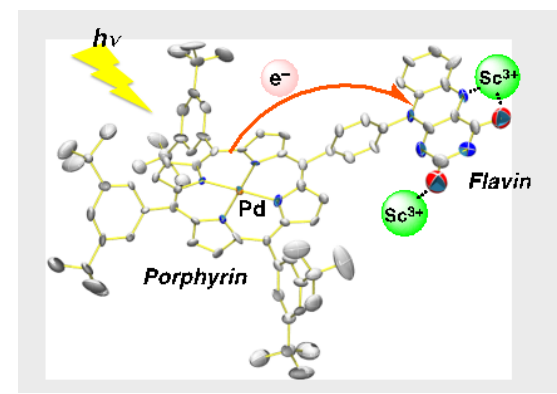

Charge Separation

T. Kojima, R. Kobayashi, T. Ishizuka,

S. Yamakawa, H. Kotani, T. Nakanishi,

K. Ohkubo, Y. Shiota, K. Yoshizawa, S. Fukuzumi

$\mathbf{\square} \mathbf{-}$

Binding of Scandium lons to Metalloporphyrin-Flavin Complexes for Long-Lived Charge Separation

Layout 2:

\section{FULL PAPER}

((The TOC Graphic should not exceed the size of this area))

Text for Table of Contents, max. 450 characters
Subject Heading

Author(s), Corresponding Author(s)*

Title 